\title{
Review
}

\section{Mechanism of psychoactive substance-induced cognitive disorders: does tau protein play a role?}

\author{
YuYe Wang ${ }^{1,2, \dagger}$, JiaCheng $\mathrm{Lv}^{3, \dagger}$, JiNing $\mathrm{He}^{4, \dagger}$, GeHua Wen ${ }^{1}$, Xu Wu ${ }^{1, *}$ \\ ${ }^{1}$ Department of Forensic Pathology, School of Forensic Medicine, China Medical University, 110122 Shenyang, Liaoning, China \\ ${ }^{2}$ Department of Neurology, The First Affiliated Hospital of China Medical University, 110001 Shenyang, Liaoning, China \\ ${ }^{3}$ Department of Plastic surgery, The First Affiliated Hospital of China Medical University, 110001 Shenyang, Liaoning, China \\ ${ }^{4}$ Cardiometabolic Medicine Center, Fuwai Hospital, National Center for Cardiovascular Diseases, Chinese Academy of Medical Science and Peking \\ Union Medical College, 100037 Beijing, China \\ *Correspondence: xwu@cmu.edu.cn $(\mathrm{Xu} \mathrm{Wu})$ \\ $\dagger$ These authors contributed equally. \\ Academic Editor: Graham Pawelec \\ Submitted: 18 September 2021 Revised: 22 November 2021 Accepted: 1 December 2021 Published: 6 January 2022
}

\begin{abstract}
Psychoactive substances are a class of chemical substances which could cause public health threats. Cognitive disorders are a category of mental health disorders that primarily affect cognitive abilities. Tau protein could maintain neuronal cytoskeleton stabilization. Post-translational modification of tau, especially phosphorylation, is an important way to regulate the structure and function of tau and phosphorylated tau is closely related to cognitive function. Lots of studies have reported the phenomenon that psychoactive substances can cause cognitive function impairment. We reviewed recent related studies and discussed them by drug classification. We mainly focused on cognitive disorders caused by acute or chronic exposure of each drugs, animal experiments and the mechanisms associated with tau phosphorylation, then compared the similarities and differences among them, trying to find out the common rules. The results suggested that tau phosphorylation is involved in psychoactive substance-induced cognitive disorder and different psychoactive substances may act by affecting amount or activity of different kinases and phosphatases in the metabolic pathway of tau. We demonstrated that tau protein is a potential target for psychoactive substances induced cognitive disorder treatments.
\end{abstract}

Keywords: Psychoactive substances; Tau phosphorylation; Cognitive disorder

\section{Introduction}

Psychoactive drugs are substances that could change individuals' consciousness, mood or thinking processes. According to 2016 global quantities of drugs seized, traditional psychoactive substances can be classified into cannabis, cocaine, opioids, amphetamine-type stimulants (ATS) and others [1]. In recent years, designer drugs, a series of synthetic substances similar to the original drugs in structure or function, have emerged continuously, featured with avoiding being classified as illicit and/or spotted in standard drug tests [2]. Some of the designer drugs have been named as "New Psychoactive Substances (NPS)" by the European Union. In addition to synthetic NPS, the consumption of some natural plants, known as plants-based NPS, has been proved to have an impact on mental status, thus arousing social concerns. The use of NPS appeared to be rapidly emerging in some low- and middle-income countries. The limited capacity of forensic, law enforcement and health experts to identify different NPS and their use makes it challenging for countries to adequately address the threat of NPS [3]. The general classification and examples are shown in Table 1.
It was reported in a cross sectional study that the prevalence of cognitive disorders (CDs) was 21\% for cannabis, $27 \%$ for stimulants and 38\% for opioids with 123 cannabis users, 100 stimulants users and 26 opioids users included [4]. Also, CDs were identified in $34.6 \%$ of patients with chronic polysubstance use disorder in a prospective, longitudinal cohort study [5]. CDs are a category of mental health disorders that primarily affect cognitive abilities. The Diagnostic and Statistical Manual of Mental Disorder, Fifth Edition (DSM-5) defines six key domains of cognitive function: executive function, learning and memory, perceptual-motor function, language, complex attention, and social cognition. The increasing cases of CDs have become a major health problem with the aging of the population worldwide [6]. Considering that psychoactive drugs could induce CDs which would increase the burden on society, it is meaningful to discuss related mechanism and provide us with new idea for prevention and treatment methods. Cerebral hemorrhage or ischemia might partly explain some CDs identified in psychoactive substances users [7]. However, the clear mechanisms need to be thoroughly investigated. 
Table 1. The classification of psychoactive substances.

\begin{tabular}{lll}
\hline Classification & Category & Example \\
\hline \multirow{4}{*}{ Traditional psychoactive substances } & Cannabis & Cannabis plants, Cannabis herb, Cannabis resin, Cannabis oil \\
& Coca/cocaine & Coca leaf, Cocaine hydrochloride, Cocaine base/paste, Other cocaine \\
& ATs & Opium, Heroin, Morphine, Pharmaceutical opioids \\
& Others & "Ecstasy", Methamphetamine, Amphetamine \\
\hline \multirow{2}{*}{ NPS } & Plant-based NPS & Khat, Kratom \\
& Synthetic NPS & Ketamine, Synthetic cannabinoids, Synthetic cathinones, Other NPS \\
\hline
\end{tabular}

Tauopathies are a group of neurodegenerative diseases closely related to CDs. Microtubule-associated protein tau is mainly expressed in neurons which maintains neuronal cytoskeleton stabilization. Post-translational modification of tau, especially phosphorylation, is an important way to regulate the structure and function of tau protein. Hyper-phosphorylated tau could be found in the brains of patients with Tauopathies such as Alzheimer's Disease (AD), progressive supranuclear palsy, and corticobasal degeneration [8,9]. For instance, AD, as a representative of Tauopathies, is featured by neuritic plaques (NPs) formed by beta-amyloid peptides(Abeta, A $\beta$ ) accumulation and neurofibrillary tangles (NFTs) formed by hyper-phosphorylated tau protein, and the latter may probably contribute to cognitive impairment $[10,11]$. Moreover, tau pathology may lead to CDs through grey matter loss [12]. Tau phosphorylation is mainly regulated by the dynamic balance of kinases and phosphatases activities [1315]. Under some pathological conditions, the quantitative or qualitative upregulation of kinases or downregulation of phosphatases would lead to tau hyper-phosphorylation and may further cause accumulation of pathological tau, contributing to CDs. Researches on glycogen synthase kinase $3 \beta$ (GSK-3 $\beta$ ), Cyclin-dependent kinase-5 (CDK-5), protein phosphatase $2 \mathrm{~A}$ (PP2A) and protein phosphatase $2 \mathrm{~B}$ (PP2B) are the most in-depth. Psychoactive substances could induce tau hyper-phosphorylation through regulation of these kinases [16-18]. Hyper-phosphorylated tau may induce pathological changes through 4 types of mechanisms, which are, causing synaptic damage by affecting intracellular tau location, altering tau degradation and truncation process, enhancing tau aggregation and changing the relation between tau and its interaction substances [19]. The abnormal phosphorylated tau could lead to CDs [20]. Meaningfully, cerebral spinal fluid t-tau, p-tau [21,22] and plasma t-tau [22] could behave as biomarkers of AD which appears to be elevated in many cases of AD at all disease stages $[21,22]$. In other disease or states with CDs, CSF ttau, p-tau and plasma t-tau may also be clinical parameters to provide basis for diagnosis. $N$-terminal fragment of tau levels even could predict future CDs and neurodegeneration [23].
In conclusion, tau phosphorylation is involved in the cognitive function impairment process and tau protein and p-tau could behave as biomarkers of Tauopathies. Based on these backgrounds, it is reasonable to speculate that tau could be a new diagnostic and therapeutic target for psychoactive substances-induced CDs. Thus, we selected 5 classes of representative drugs in psychoactive substances and reviewed related CDs and increasing of phosphorylation level of tau protein induced by them in detail and introduced other psychoactive substances-induced CDs briefly. We aim to explore the role of tau protein or tau phosphorylation in psychoactive substances-induced CDs.

Three independent reviewers separately conducted the literature search on two databases, PubMed and Google Scholar. Our search strategy contained three keywords: "psychoactive substances", "tau phosphorylation" and "cognitive disorders". Several synonyms were also included. The final literature search was performed on May 15th, 2021. We mainly searched relevant articles from the past 20 years which were published in English. Then duplicates within the retrieved articles were removed and divergences between the reviewers were discussed and resolved. In the initial search, studies were screened based on the content of title and abstract. After that, we obtained the full text of the retrieved studies and carefully read them to decide whether the full text meets with inclusion criteria or exclusion criteria. The inclusion criteria encompassed original works (including clinic studies and animal experiments) on the relationship between use of psychoactive substances and CDs in which tau phosphorylation plays a role. Studies that emphasizes other mechanisms unrelated to tau phosphorylation were excluded. And studies lacking a control group were also excluded.

\section{Opioids}

Opioids refer to natural medicines and semi-synthetic derivatives originating from opium which act on opioid receptors including $\mu, \delta$ and $\kappa$ [24]. Pain relief, including anesthesia, is the primary medical use of opioids. Opioids are often non-medically consumed for its strong effect of euphoria [25]. According to world drug report 2021, in 2019, an estimated 62 million people, or 1.2 per cent of the global population, used opioids at least once in 2019 
[3]. Morphine, a representative opioid, consists of five condensed rings with a phenolic hydroxyl group at position 3, an alcohol hydroxyl group at position 6 and tertiary amine formed by the nitrogen $(\mathrm{N})$ atom at position 17 which all exert important pharmacological roles [26]. For example, codeine is formed when morphine is O-methylated at position 3 the analgesia effect of which would reduce. Heroin is formed when morphine is $\mathrm{O}$-acetylated at both position 3 and 6 which could pass through blood brain barrier more easily [24]. Opioids abuse took up 68 percent of all overdose deaths in 2017 [1]. In human researches, visual-spatial memory and working memory are damaged in heroin consumers and opioid-substituted patients [27,28]. Besides, impaired executive function and attention have been reported in heroin users and buprenorphine or methadone maintenance patients [27,29,30]. Moreover, acute use of morphine can cause transient anterograde and retrograde memory impairment in users [31].

Acute use of morphine has been shown to impair memory and learning function in different animal models. Memory impairment was detected by dark compartment test in male mice [32] and radial maze test in male SpragueDawley (SD) rats [33]. As to the investigation of chronic effects on cognitive functions, researchers have found that morphine could impair spatial learning and memory [3437], especially short-term [35,36]. Meanwhile, object location memory could be impaired when tested by objectlocation memory task and elevated plus maze testing [38]. Besides, Wang et al. [39] implied that repeated morphine injection caused attention deficits and less cognition flexibility manifested by elevated omission and reduced accuracy. Surprisingly, voluntary exercise has been found to ameliorate the CDs that are induced by chronic morphine. Thus, voluntary exercise might be a potential method [37].

As for underlying mechanisms, opioid usage is associated with greater tau concentration in the brains of young opioids users [40]. The level of p-tau in any region of brain is significantly related to duration of opioids consumption. Analysis of hyper-phosphorylated tau in hippocampus, brainstem and basal ganglia indicated an excess of a pathogenic form of NFT (AT8-positive NFTs). Ramage et al. [41] reported that opiate could increase the deposition of hyper-phosphorylated tau at Thr231 and Ser202 sites in the hippocampus subiculum, entorhinal cortex, the neocortex, the locus coeruleus and the nucleus basalis of Meynert of young drug abusers when compared to those agematched controls. Tau phosphorylated at Thr231 (AT180) is more widespread than at Ser202 (AT8) [41] as abnormal phosphorylation of tau is considered to start from Cterminal to $N$-terminal [42]. They further suggested that drug users show early AD-related brain pathology which is characterized by hyper-phosphorylated tau that may be the basis for CDs [43].

In rat embryo cortical neurons, morphine could induce increased phosphorylation of tau at tau1 (Ser199/Ser202),
Ser396 and Ser404. Mitogen-activated protein kinases (MAPKs) may be a significant participator in AD neurodegeneration. c-Jun NH2-terminal kinases (JNK), members of MAPKs sub-group can upregulate phosphorylation of tau protein and deposition of amyloid protein. After morphine treatment, the level of phosphorylated JNK increased. In addition, the phosphorylation level of p38-MAPKs, another sub-group of MAPKs family, increased in a time-dependent manner after $10 \mu \mathrm{m}$ morphine exposure, which further led to an increase of phosphorylated tau protein. However, the current study showed that SP600125, an inhibitor of JNK or SB203580, an inhibitor of p38 MAPK only significantly attenuated tau hyper-phosphorylation at Ser396 site while there was little change in the level of tau hyperphosphorylated at tau- 1 and Ser404 sites, which implied that JNK or p38-MAPK contributed to but were not the only determinant factor of tau phosphorylation [44]. Major kinases of tau (i.e., CDK5 and GSK-3 $\beta$ ) were found upregulated in victims' and animals' use of opioids $[43,45]$. Moreover, downregulation of tau phosphatases also plays important role in increasing tau phosphorylation, such as PP1, PP2A and PP3. Opioids could upregulate PP1-specific endogenous inhibitors, which would not only lead to elevated phosphorylated tau, but also exacerbate damage of the brain from a repeated opioids exposure [46]. Besides, opiates could downregulate the activity of PP2A through demethylation, which would result in tau hyper-phosphorylation $[47,48]$. The corresponding possible mechanism diagram is shown in Fig. 1. Besides, researchers found that phosphorylated tau involved more anatomical region of the brain in heroin abusers compared to controls in which frontal cortex and fusiform gyrus are more sensitive to effect of heroin addiction. Tau protein in anatomical areas related to cognitive function might be easier to be phosphorylated. And age related tau phosphorylation is considered to be accelerated by heroin abuse [49].

According to world drug report, the global opium market is still expanding. At the same time, many studies have pointed out that opioids can lead to CDs in acute or chronic experiments. Studies of tau protein suggest that tau phosphorylation plays a critical role in CDs induced by opioids, with JNK/p38 MAPK involved in phosphorylation of tau upstream. Mechanism research can provide potential therapeutic targets for CDs caused by opioid abuse.

\section{Amphetamine-type stimulants (ATS)}

\subsection{3,4-methylenedioxymethamphetamine (MDMA)}

MDMA, a kind of amphetamine-type stimulants with methylenedioxy substitution on the phenyl ring, has both hallucinogenic and stimulant actions at relatively low doses [50]. Known as ecstasy, MDMA is often used in dance clubs due to its acute euphoric and hallucinogenic properties [51,52]. Nearly 20 million people globally are estimated to have used "ecstasy" in 2019 [3]. The quantities of "ecstasy" seized worldwide increased to 14 tons in 2016 [1]. 


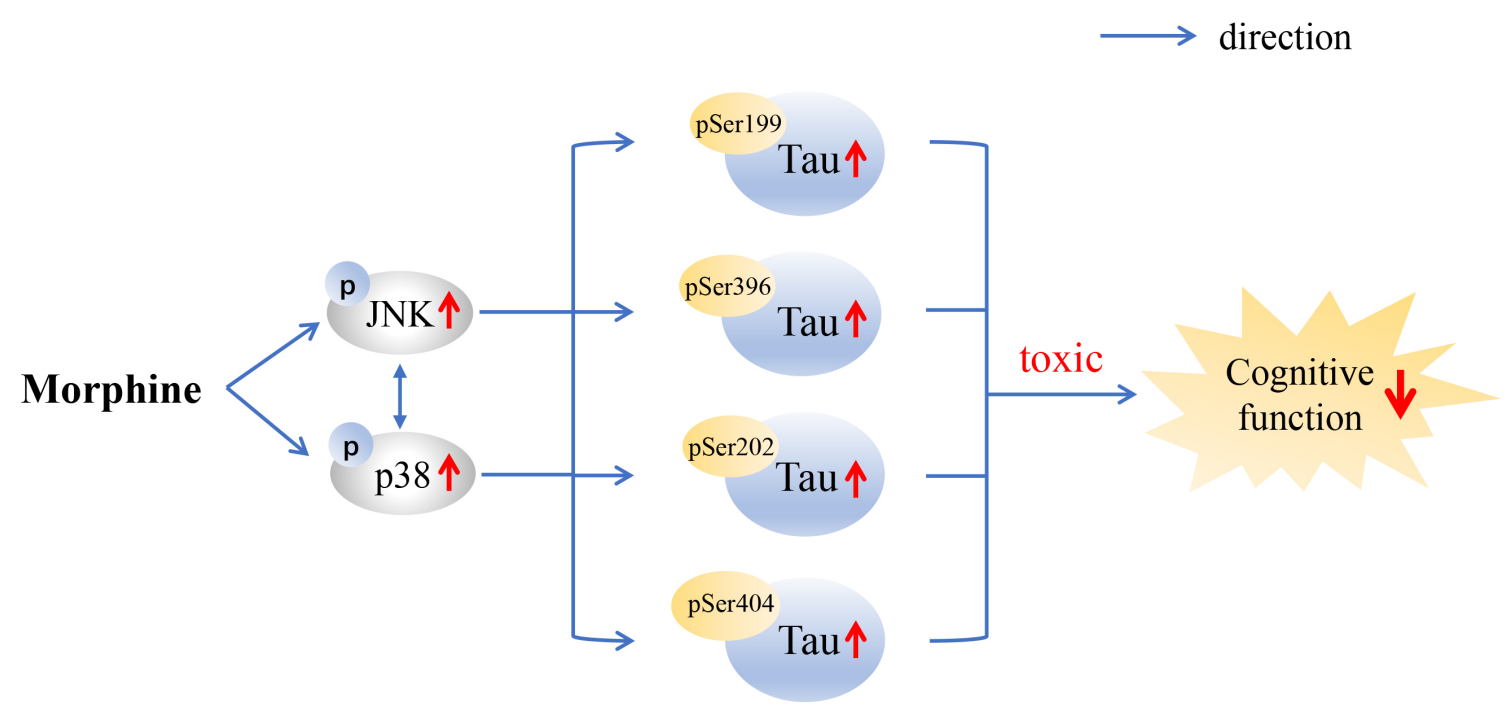

Fig. 1. Possible mechanism of morphine-induced-tau phosphorylation at different sites. Morphine treatment increase the phosphorylation level of JNK and p38, which in turn increase the expression of p-tau-Ser199, Ser202, Ser396 and Ser404, causing CDs. CDs, cognitive disorders; JNK, c-Jun NH2-terminal kinase.

Despite its neurotoxicity [51-54], there have also been studies testing the potential role of MDMA used in assisted psychotherapy of post-traumatic stress disorder (PTSD) [55]. In chronic users of MDMA, Wunderli et al. [56] found that heavy use of MDMA only is correlated with deficits in declarative memory, while additional dysfunction in working memory and executive functions appeared in poly-drug MDMA users. As for social cognition, they pointed out that people with long-term MDMA use might show an impairment in cognitive empathy capacity [57]. Furthermore, the CDs caused by dependence or abuse of MDMA could not be reversed by a 6-month prolonged abstinence [58]. In animal experiments, the results indicated that MDMA treatment leads to dose-dependent impairments of spatial learning and memory [59] and repeated treatment of MDMA impaired working memory and reduced cognitive flexibility [60]. Moreover, MDMA may exacerbate 1-methyl4-phenyl-1,2,3,6-tetrahydropyridine (MPTP)-induced-CDs [61] and social stress plus MDMA enhanced the risk of developing CDs [62]. These results implied that exposure to MDMA may intensify the effects of other neurotoxic factors. However, physical exercise could decrease these harmful effects of MDMA, probably through decreased mitochondrial dysfunction [59].

In further studies, MDMA decreased mitochondrial trafficking in primary cultured neurons of hippocampus. This effect was correlated with CDs in a tau-related manner in which GSK-3 $\beta$ activity was influenced and phosphorylation level of tau increased, especially in Thr181 residue [63]. In a mouse model of $A D$, a study suggested that hippocampal accumulation of phosphorylated tau would lead to abnormal mitochondrial kinetics, changes of mitochondrial structure and function, and hippocampal based learning and memory deficits [64]. Busceti et al. [65] pointed out that acute or repeated MDMA treatment could induce tau phosphorylation at Ser396 and Ser404 which was limited to the stratum radiatum of the CA2 area and the stratum lucidum and stratum radiatum of the CA3 area while there was no increase in the pyramidal cell layer of CA2 or CA3 area or other hippocampal regions. A dysfunction of $\mathrm{CA} 3$ neurons caused by tau phosphorylation might be responsible for $\mathrm{CDs}$ because the responsivity of the CA3-CA1 synapse seems to be correlated with associative learning [66]. As for the mechanisms of tau phosphorylation, GSK- $3 \beta$ and CDK-5 are two major enzymes involved in regulation of tau phosphorylation. GSK-3 $\beta$ activity is negatively regulated by the canonical winglesstype mouse mammary tumor virus (MMTV) integration site family (Wnt) pathway. After injection of MDMA, we found that Wnt pathway was inhibited, which followed the increase of Dickkopf-1(Dkk-1), and thus further led to an increase of GSK-3 $\beta$ activity. The level of Ser9phosphorylated GSK-3 $\beta$ was also involved in the negative regulation of activity of GSK-3 $\beta$. Besides, there was an increase in hippocampal levels of p35, p25, and CDK5 in mice treated with MDMA. The corresponding possible mechanism diagram is shown in Fig. 2. However, there are conditions that learning deficit could be detected when tau hyper-phosphorylation could not be detected any more [65]. Thus, tau hyper-phosphorylation may be involved in, but is not the only decisive factor of MDMAinduced CDs. Besides, MDMA could increase the Ser199phosphorylated tau protein independent of canonic pathway involving phosphorylated protein kinase B (AKT), CDK-5 and GSK-3 $\beta$ [67] which indicated that definite mechanism of MDMA-induced-tau phosphorylation needs further in- 


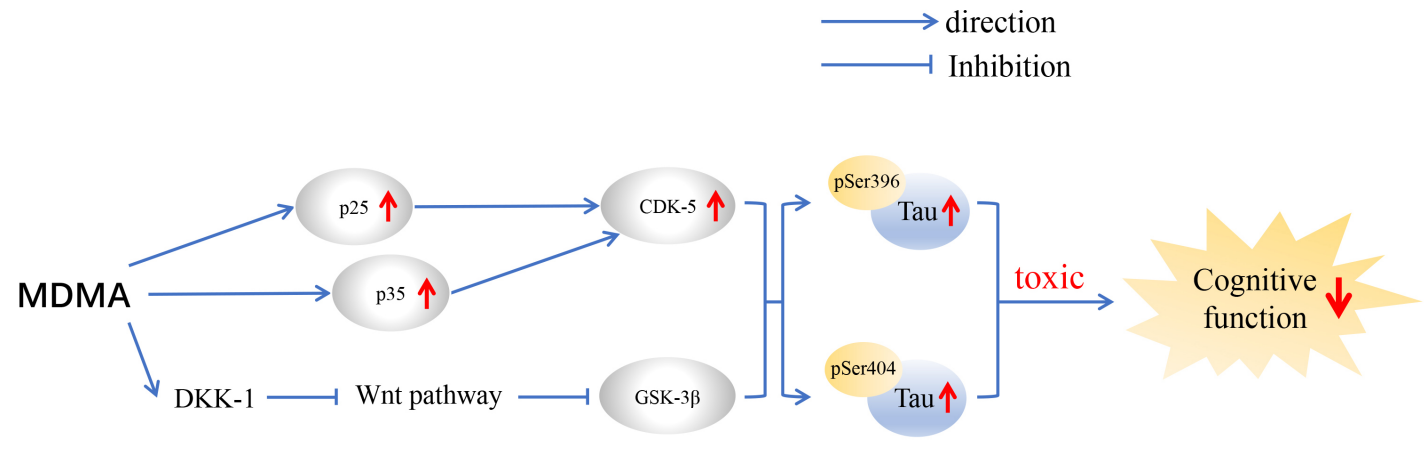

Fig. 2. Possible mechanism of MDMA-induced-tau phosphorylation at different sites. MDMA induced neurotoxicity through the increase of p35, p25 and CDK-5 levels and further lead to tau phosphorylation. Besides, MDMA treatment leads to increase of DKK-1, followed by inhibition of Wnt pathway and inhibition of GSK-3 $\beta$ activity. In conclusion, MDMA increases the level of CDK-5 and activates GSK $3 \beta$, which in turn increase the expression of p-tau-Ser396 and Ser404, causing CDs. CDK-5, Cyclin-dependent kinase-5; CDs, cognitive disorders; MDMA, 3,4-methylenedioxymethamphetamine; Dkk-1, Dickkopf-1; GSK-3 $\beta$, glycogen synthase kinase $3 \beta$; METH, Methamphetamine.

vestigation. Additionally, MDMA evoked an increase in tau phosphorylation (Ser396) in the hippocampus, striatum and cerebellum in the aged rats while there were no significant differences in adolescent group [68], which suggests a possible susceptibility to MDMA-related toxic events for the old.

\subsection{Methamphetamine (METH)}

METH, a kind of amphetamine type-stimulants derive from the $\beta$-phenylethylamine core structure [50], is widely abused for its stimulant, euphoric, empathogenic and hallucinogenic effects [69]. D-Methamphetamine, is a stronger psychostimulant, with 3-5 folds the central nervous system (CNS) activity when compared with L-methamphetamine. However, both enantiomers could affect dopamine release and induce stereotypy and psychosis at high doses [70]. Markets of METH are extending, which is one of the most worrying threats of drug use [1]. METH have not only neurotoxic [71] but also neuroprotective effects [72] when low doses of METH were administered within $12 \mathrm{~h}$ after severe traumatic brain injury (TBI) in rodents, which elucidates its therapeutic potential [73]. In chronic METH users, CDs occurred frequently as measured by Montreal Cognitive Assessment (MoCA) [74] especially in concentration and memory [75]. A meta-analysis revealed impairment in most cognitive domains [76]. 6-7-year old children with prenatal METH exposure scored significantly lower than controls on cognition in several domains [77]. Besides, a 12-week aerobic exercise may have beneficial effects on METH dependent patients with verbal learning and memory deficits [78]. In animal studies, chronic METH treatment could also impair cognitive functions [79-83], including deficits in reversal learning [79], disorders in alert exploratory behavior [80], impairments in recognition memory [81] and so on. In addition, Seyedhosseini et al. [82] pointed out that repeated METH administration impaired only long-term recognition memory in somehow dose dependent manner while short-term remained unchanged.

As for further explorations on mechanism, researchers suggested that METH induced neurotoxicity probably by promoting abnormal tau phosphorylation in N2a cells [84], PC12 cells [85] or SH-SY5Y cells [86], where p-tauSer199, p-tau-Ser214 [84], p-tau-Ser396 [84,85] and p-tauThr205 [86] levels increased correspondingly. In addition, they found that the expression of p-GSK-3 $\beta$-Tyr216 was elevated after METH exposure, which implies an activation of GSK-3 $\beta$ [84,85]. METH upregulated the expression of phosphorylated insulin receptor substrate-1 (IRS1) at Ser307 [84] and downregulated the expression of pinsulin receptor (IR) at Tyr1355 as well as p-IRS1 at Tyr896 [86], which implied an inhibition of insulin signal pathway. Besides, METH decreased the expression of AKT [18], another key insulin signal protein at Ser473 [84,86]. Thus, METH significantly decreased insulin signal and further induced downstream GSK-3 $\beta[84,86]$ and GSK$3 \alpha$ [86] activation and tau phosphorylation. In parallel, METH decreased the expression of phosphorylated extracellular regulated protein kinases (ERK) at Thr202 and Tyr204 which activated ERK and in turn induced tau phosphorylation [86]. Another similar experiment indicated that METH increased the p-Ser396-tau protein level in SHSY5Y cells, primary cultured neurons and in mice brains. Furthermore, reducing $\alpha$-syn level could relieve p-Ser396tau overexpression and knocking out tau can effectively inhibit METH induced $\alpha$-syn overexpression in mice brains [87] while another study from the same research group reported that tau phosphorylation might be indirectly promoted by excess $\alpha$-syn through GSK $3 \beta$ and CDK5 [88] in which both tau phosphorylation and $\alpha$-syn contributed to METH-induced neurotoxicity in mice brains, indicat- 


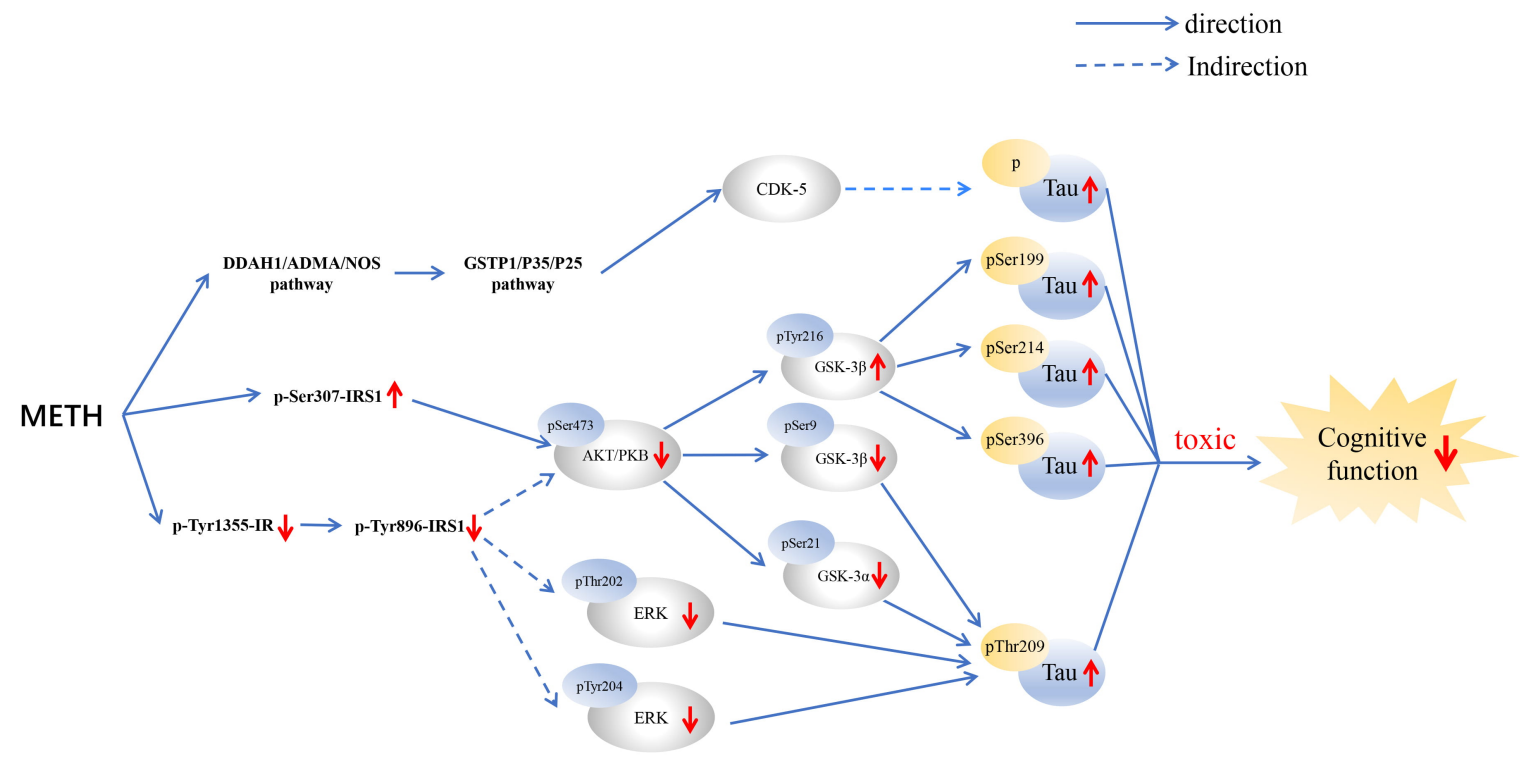

Fig. 3. Possible mechanism of METH-induced-tau phosphorylation at different sites. METH induced neurotoxicity through the activation of DDAH1/ADMA/NOS pathway, further resulting in activation of GSTP1/p35/p25/CDK-5 pathway which could further lead to tau phosphorylation. Besides, the insulin signal is transmitted through IR and IRS1. METH treatment leads to AKT phosphorylation (inhibition of insulin pathway). AKT phosphorylates GSK3 $\beta$ and GSK3 $\alpha$ in different phosphorylation sites including Ser199, Ser214 and Ser396 (inhibition of kinase activity). In parallel, p-IRS1 actives MAPK/ERK cascade, both of the two pathways are participated in p-tau-Thr209 regulation. In conclusion, METH activates CDK-5, GSK3 $\alpha / \beta$ and ERK, which in turn increase the expression of p-tau, causing CDs. AKT, protein kinase B; CDK-5, Cyclin-dependent kinase-5; DDAH1/ADMA/NOS, dimethylarginine dimethylaminohydrolase 1/asymmetric dimethylated L-arginine/Nitric Oxide Synthase; ERK, extracellular regulated protein kinases; GSTP1, glutathione S-transferase P1; IR, insulin receptor; IRS1, insulin receptor substrate-1; GSK-3 $\beta$, glycogen synthase kinase 3 $\beta$; MAPK, Mitogen-activated protein kinase.

ing an vicious circle between $\alpha$-syn and tau in METH abusers. Xiao et al. [89] pointed out that METH exposure significantly upregulated the expression of phosphorylated tau at Ser396 and Thr231 sites in a dose- and time-dependent manner both in vivo (hippocampus of SD rats) and in vitro (SH-SY5Y cells). METH induced oxidative stress damage through the activation of dimethylarginine dimethylaminohydrolase 1 /asymmetric dimethylated L-arginine/Nitric Oxide Synthase (DDAH1/ADMA/NOS) pathway, further resulting in activation of glutathione S-transferase P1 (GSTP1)/p35/p25/CDK-5 pathway [90]. The corresponding possible mechanism diagram is shown in Fig. 3. Besides, it has been reported that enhanced CDK5 activity and translocation of p35 to membrane were detected in the ventral striatum of acute and chronic METHtreated rats [91].

In summary, ATS can cause various damages to the human body. Multiple studies have demonstrated its deleterious effects on the CNS, and the impairment is irreversible even after abstinence. At the same time, studies on tau protein suggest that we can delay the impairment progress by interfering tau phosphorylation which may involve changes in kinases, either GSK-3 $\beta$ or CDK-5, providing a further target upstream of the tau.

\section{Cocaine}

Cocaine, or benzoylmethylecgonine, is a kind of tropane alkaloid that is extracted from the leaves of the coca plant, which is ground into a paste and contains $70 \%$ pure cocaine $[92,93]$. It is usually treated with acid to form cocaine hydrochloride $(\mathrm{HCl})$ salt which makes it water soluble and so can be absorbed through the nasal mucosa [93]. It is a strong stimulant mostly used as a recreational drug [94] which often acts as a CNS stimulant and as an appetite suppressant [95]. In the medical utility of cocaine, it can be used as a local numbing agent to help with painful procedures [96]. However, excessive and repeated cocaine consumption is also associated with an increased risk of a range of somatic, psychological and social problems, such as psychosis and aggression [97-99]. An estimated 20 million people used cocaine in 2019 , corresponding to 0.4 per cent of the global population [3]. Because of its high addictive potential and harmful effects on mental and physical wellbeing $[100,101]$, the use of cocaine is a major public health issue with substantial social and economic costs [100].

Up to now, studies on acute cocaine administration have suggested enhancement of response inhibition and psychomotor speed [102]. As for response inhibition, previous study indicated a dose-effect relationship of im- 
paired response inhibition [103] and a significant increase in the number of responses per second after cocaine treatment [104]. Notably, it was concluded that interference of cocaine with cognitive impulse control and functional corticostriatal connectivity depends on the dopamine $\beta$ hydroxylase enzyme (DBH) genotype [106]. For another, long term effects of cocaine showed a wide array of deteriorated cognitive functions rather than with specific CDs [106]. When consumed over an extended period of time, cocaine was associated with deficits in attention, verbal learning/memory, and working memory constructs [107] and the group of patients with serious cocaine dependence may have difficulty in recovering from memory and attention deficits in short term [108]. Moreover, cocaine users performed worse in the Tic Tac Toe task, a spatial working memory task [109]. When it comes to the reversibility of long-term cocaine-induced disorders, users who ceased taking cocaine seemed to recover completely, which suggest that cognitive impairment might be reversible within 1 year [110]. But increased depression and anxiety are specifically related to more cognitive control breakdowns toward cocaine cues in veterans [111]. Cocaine has been shown, in animals, to acutely increase dopamine release in the mesocorticolimbic brain reward system, and conversely, to cause hypodopaminergic activity in the prefrontal cortex when administered chronically [112,113]. In other words, cocaine imposed different effects upon cognitive function according to different administration schedule and affect different brain regions. For instance, cocaine has been proved to improve the marmosets' recognition memory when given acutely post sample, whereas it had a detrimental effect after the repeated exposure [114]. Another related research found that cocaine-naïve monkeys performed better in stimulus discrimination and reversal task compared to monkeys who had previously self-administered cocaine [115].

As for the underlying mechanisms of cocaine-induced CDs and the role of tau plays in this process, certain achievements have been made. Researchers found that the levels of phosphorylated tau at Ser199/202 and Ser396/404 in paired helical filaments (PHFs), a critical component of neurofibrillary tangles in $\mathrm{AD}$, were elevated in rat brain hippocampus, cortex, and caudate-putamen on day 8 and day 16 after the injection of cocaine compared with saline control rat at the same brain regions. Furthermore, although CDK5 is an immediate downstream target of cocaineregulated transcription factor and cocaine injection could induce significant hyper-phosphorylation of tau, the overexpression of CDK5 and p35 was not detected, suggesting that hyper-phosphorylation of tau and neurofilament caused by cocaine may not correlate to $\mathrm{CDK} 5$ or p35. It is reasonable to speculate that cocaine might induce imbalance of multiple protein kinase and protein phosphatases, and further leading to hyper-phosphorylation of tau and neurofilament observed in the study [116]. Another related research used SH-SY5Y to examine the hypothesis that co- caine may affect the metabolism of tau protein and would lead to changes in neurotransmitter uptake and release. The results implied that cocaine treatment caused no significant changes in total protein, however, it resulted in a reduction in tau protein in the cytoplasmic and membrane fractions, which proves that along with ultrastructural nuclear changes in the brains of cocaine abusers [117]. These contradictory outcomes indicated that the impact of cocaine on tau proteins may be paradoxical in different brain tissues. The action of cocaine on tau as well as other proteins, enzymes and neurotransmitters should be further explored in more comprehensive ways.

\section{Ketamine}

Ketamine, a derivative of phencyclidine (PCP), first aimed at lessening the serious psychodysleptic side effects and abuse potential of the parent drug [118] and provided as an anesthetic agent and analgesic drug in low doses [119121]. The use of S-ketamine is increasing globally, because the S-enantiomer has been reported to be four folds more effective anesthetic and analgesic than the R-enantiomer and about two folds more potent than the racemic mixture of ketamine [121]. Many studies have demonstrated significant and rapid antidepressant effect of ketamine [122]. However, ketamine is still a drug with potent hallucinogenic property when repeatedly used over a sustained period, thus emerging as a kind of NPS and is abused worldwide, especially in East and South-East Asia [123,124]. In analgesic process, Kim et al. [125] found that patients with Complex Regional Pain Syndrome who received long-term frequent ketamine treatment showed CDs compared with those who did not. Besides, after initial sedation and administration of $0.3 \mathrm{mg} / \mathrm{kg}$ ketamine in elderly patients during ophthalmic surgery, the researchers detected changed cognitive status as measured by the short portable mental status questionnaire (SPMSQ), which is an immediate effect of ketamine [126]. Furthermore, several studies demonstrated that ketamine could induce CDs in healthy volunteers in acute experiment. Some results implied that ketamine impaired several domains of cognition [127]. Moreover, ketamine injection could impair verbal learning and recall [128]. As for chronic use of ketamine, worse verbal and visual memory performance [129] and other tests related with CDs were detected in chronic ketamine users [130]. Compared with METH, the ketamine-dependent patients impaired cognitive function more [131]. In addition, Liao Y et al. [132] demonstrated that abnormalities of white matter in bilateral frontal and left temporoparietal regions is correlated with prolonged ketamine use in dose-dependent manner which suggested a microstructural base for the alternations in cognition and experience in people with chronic ketamine use. In acute experiment of rodents, Nikiforuk A. et al. [133] suggested that ketamine impair cognition function of SD rats when assessed by attentional set-shifting task (ASST) and novel object recognition task (NORT). When ketamine 
was administered to pregnant rats in the second trimester, CDs in offspring could be detected by Morris Water Maze (MWM) [134,135]. Furthermore, mice treated with ketamine in perinatal period showed dysfunction in a task of cognitive flexibility and abnormality in spontaneous alternation and deficits in NORT [136]. In chronic experiment of male C57BL/6 mice $[137,138]$ or Institute of Cancer Research (ICR) mice $[139,140]$, researchers found that ketamine intraperitoneal injection caused CDs when tested by Radial Arm Maze [137], MWM [137,139,140] or Y Maze [138].

When it comes to the underlying details of ketamineinduced CDs, by establishing a model of 6 monthsketamine administration in wild-type (C57BL/6) and Tau knockout mice, Li et al. [141] investigated the effects of different doses of ketamine administration on tau protein expression and phosphorylation in the mouse hippocampus and changes in $\alpha$-amino-3-hydroxy-5-methyl-4-isoxazolepropionic acid (AMPA) receptor expression in the synaptic membrane. The results showed that long-term ketamine administration led to excessive tau protein phosphorylation at Ser202/Thr205 and Ser396 but not at Ser199, Ser262 and Ser404 [17] and that long term ketamine administration decreased AMPA receptor levels in the hippocampal cell membrane in a tau protein-dependent pattern, which revealed the role of tau protein phosphorylation in the mechanism of ketamine neurotoxicity [141]. The phosphorylation was mediated by increase in the activity of GSK-3 $\beta$ (at high doses) and CDK5 (long-term) and a decrease in the activity of PP2A [17]. However, another research reported that after 6 month-administration of ketamine there was a significant increase of hyper-phosphorylated tau at Ser199 in the layer I of prefrontal cortex of mice and in the outer layers of prefrontal cortex and deep layers of entorhinal cortical sections of monkeys. Moreover, this research also indicated that there might be a relationship between hyper-phosphorylation of tau and apoptosis. Therefore, the long-term ketamine toxicity might involve neurodegenerative process similar to that of aging or $\mathrm{AD}$, which is another example of chronic experiment [142]. Besides, research showed that in acute experiment, levels of phosphorylated tau mRNA and hyper-phosphorylated tau at Ser404 significantly increased at 14 days after ketamine anesthesia in developing hippocampal tissue of neonatal rats [143]. In animal anesthesia, hyper-phosphorylation of tau at Ser396, Ser262, Thr181 and Ser202/Thr205 were observed 1 hour after ketamine/xylazine treatment in a dose-dependent manner in which ketamine/xylazine mixture is one of the most commonly used anesthetic agents in animal research and veterinary practice. Calmodulin-dependent protein kinase II (CaMKII) is the major upstream molecular event [144]. Considering all four experiment results, we could found that ketamine induced tau phosphorylation at different sites and different brain regions which may be caused by different doses and treatment time.
In recent years, postoperative cognitive dysfunction aroused increasing attention, when ketamine is used as an anesthetic, and we can reduce the dose or frequency to prevent CDs. In the condition that ketamine administration could induce CDs in offspring of pregnant rats or in mice treated in perinatal period, understanding the longterm damage of ketamine plays an important role, especially when some studies have indicated that CDs persists even after withdrawal.

\section{Synthetic cannabinoids}

Synthetic cannabinoids (SCs) first came out in the 1980s as laboratory research tools [145]. SCs have become popular recreational drugs among young adults in the USA [146]. They were usually advertised to contain only 'legal' and 'safe' compounds [147], leading to a misunderstanding of their harmfulness including adverse reactions, dependence, long-term effects and psychiatric consequences [148]. Mostly lipophilic and nonpolar, SCs generally consist of about 22 to 26 carbon atoms with a side chain of 4-9 saturated carbon atoms [149]. The structure makes them volatile when smoked and thus SCs were mainly consumed through smoking, inhalation and insufflation [150]. A model was proposed in order to summarize the chemical structures of the occurring SCs. The model structure consists of four key structural elements, namely "the core and substituents", "the link", "the ring and substituents" and "the tail" which signify altering positions. This method allowed the chemical structure of the SCs to be identified without the long chemical name [149].

SCs have been reported to represent more than half of the total NPS-related seizures in Europe in 2014 [151]. In the medical use, SCs are reported to be anti-inflammatory, antiemetic, analgesic, antineoplastic [152]. Acute psychotic reactions in healthy individuals could occur after a single or repeated use of $\mathrm{SC}$, and may include a wide range of CDs [153]. In the research of Schwartz MD et al. [154], two outbreaks of agitated delirium were linked to the administration of the same previously unknown SCs. Moreover, SCs could exacerbate symptoms in patients already diagnosed with psychotic illness [155]. As to chronic effects, under the influence of long-term SCs, disturbance of fine motor skills, impairment of attention and concentration were found [156]. For another, SC users were found to have impairments in long-term memory and working memory, which was similar to recreational cannabis users [157]. Over the years, the effects of SCs have been investigated widely by performing an extensive range of tests in animal behavioral models [151]. Acute SC administration in rodents produced the cannabinoid tetrad of effects and dose-dependent anxiolytic and anxiogenic properties were found. Chronic SC administration produced CDs in rodents, especially exposed during adolescence [158]. Indeed, high doses of JWH-25 and JWH-073 induced convulsions, myoclonias and hyperreflexia in mice, which were 
not usually observed after the administration of traditional cannabis [159].

When it comes to the underlying mechanisms of SCsinduced $\mathrm{CD}$ and the role phosphorylation of tau plays in this process, certain achievements have been made. Until now, two subtypes of cannabinoid Gi/o-coupled receptors, CB1 and $\mathrm{CB} 2$, have been totally found and identified. CB-1 receptors are found mainly in CNS, which could reduce cyclic adenosine monophosphate concentrations when stimulated. And CB-1 stimulation could cause hypothermia, analgesia, cataplexy, and locomotor suppression. Meanwhile, SCs also stimulate CB-2 receptors, which are mainly found in immune and hematopoietic cells [160]. Several findings indicated that the activation of both $\mathrm{CB} 1$ and $\mathrm{CB} 2$ receptors by natural or synthetic agonists, had certain beneficial effect by reducing the harmful tau phosphorylation, as well as by promoting the brain's intrinsic repair mechanisms [161]. For another, chronic treatment with arachidonyl2-chloroethylamid (ACEA), a kind of CB1 selective agonist, reduced the levels of tau phosphorylated at Thr181 site in treated APP/PS1 mice [162]. As to the specific role for $\mathrm{CB} 2$ receptor in the modulation of tau phosphorylation, the administration of the CB2 receptor agonist JWH-133 has been proved to reduce phosphorylation of tau, thus reversing neurodegeneration, neuro-inflammation and spatial memory impairment in the okadaic acid (OKA)-induced AD model [163], along with another similar research shows that chronic JWH-133 administration reduced tau hyperphosphorylation in APP/PS1 mice [164]. For the details, recent study showed that JWH133 reduced phosphorylation of tau and GSK $3 \beta$ activity in HEK293 tau cells, but the effects of JWH133 on phosphorylation of tau and GSK $3 \beta$ disappeared while blocking Adenosine Monophosphate Activated Protein Kinase (AMPK) activity, which indicated that the deletion of CB2R induced behavior damage and ADlike pathological alternation probably via AMPK/GSK3 $\beta$ pathway [165]. However, SCs have been reported to exhibit higher binding affinity at both $\mathrm{CB} 1$ and $\mathrm{CB} 2$ subtypes, and also to display varying intrinsic activity relative to $\Delta 9$ tetrahydrocannabinol $(\Delta 9-\mathrm{THC})[166]$. So the CDs caused by SCs may have a strong connection with the inhibition of NO-dependent tau hyper-phosphorylation. From the research of Giuseppe Esposito et al. [167], results demonstrated that SCs down-regulated inducible nitric oxide synthase (iNOS) protein expression and NO production in C6 cells and that WIN55, 212-2 inhibited tau protein hyperphosphorylation in $\mathrm{A} \beta$-stimulated $\mathrm{PC} 12$ cells.

In summary, despite the fact that the SCs has a great many research and clinical values with anti-inflammatory, antiemetic, analgesic, antineoplastic functions, it also goes hand in hand with many psychotic problems, especially a wide range of CDs. Contrary to most of the psychoactive substances we have discussed, the SCs play a role mainly through down-regulation of harmful tau phosphorylation rather than contributing to tau phosphorylation, which suggests that SCs may pose neuroprotective properties and could have pharmacological and therapeutic potential. Nevertheless, considering the inherent danger that may accompany use of SCs, more detailed and profound researches need conducting before applying the mechanism to clinical practice.

\section{Other psychoactive substances}

Cannabis contained more than 550 chemical compounds, with more than 100 phytocannabinoids and aromatic terpenes being identified, including $\triangle 9$-THC and cannabidiol (CBD). These phytocannabinoids exert functions by binding to the cannabinoid receptors and other receptor systems [168]. It was estimated that roughly 200 million people used cannabis in 2019, representing 4 per cent of the global population. The number of cannabis users has increased by nearly 18 per cent over the past decade [3]. A meta-analysis showed that reduced cognitive functioning was associated with frequent or heavy cannabis use in adolescents and young adults [169], the underlying mechanism of which might be synaptic pruning and white matter development [170]. Moreover, there are gender differences in the impact on cognitive function [171]. Some of the effect of cannabis on cognition is similar to SCs due to similar active ingredients. Many research results suggested that high-dose cannabis or long-term use would cause CDs, while low-dose do not impair cognition and may even exert a protective or therapeutic effect [169,172-175].

Khat, a kind of plant-based NPS, is made from the leaves and shoots of an Arabian bush, which are chewed or made into tea and act as a stimulant [176,177]. Khat contains more than 40 compounds, including alkaloids, glycosides, tannins, flavonoids, terpenoids, amino acids, vitamins, and minerals. However, the main active ingredients are cathine and cathinone which are structurally related to amphetamine $[178,179]$. Several human studies [176] suggest that chronic khat use is associated with significant impairments in several cognitive domains, including inhibitory control [180], cognitive flexibility [181], working memory [181,182], behavioral control [183], learning [184], motor speed/coordination [184] and set-shifting/response inhibition [184]. Besides, research reported that only concurrent use of khat and tobacco would impair working memory [185], verbal learning and delayed recall deficits [186] while khat only users and nonusers were comparable $[185,186]$ which are inconsistent with studies mentioned above. However, these results should arouse our attention in the CDs appeared in concurrent users. Several studies in animals also reported the CDs caused by khat in a dose and time dependent manner [176,187-189].

Kratom, leaves from tropical tree, causes stimulant and sedative effects in different doses. Raw leaves could be chewed directly or it could be swallowed as a pill, crushed and smoked and brewed as a tea [190]. Kratom 


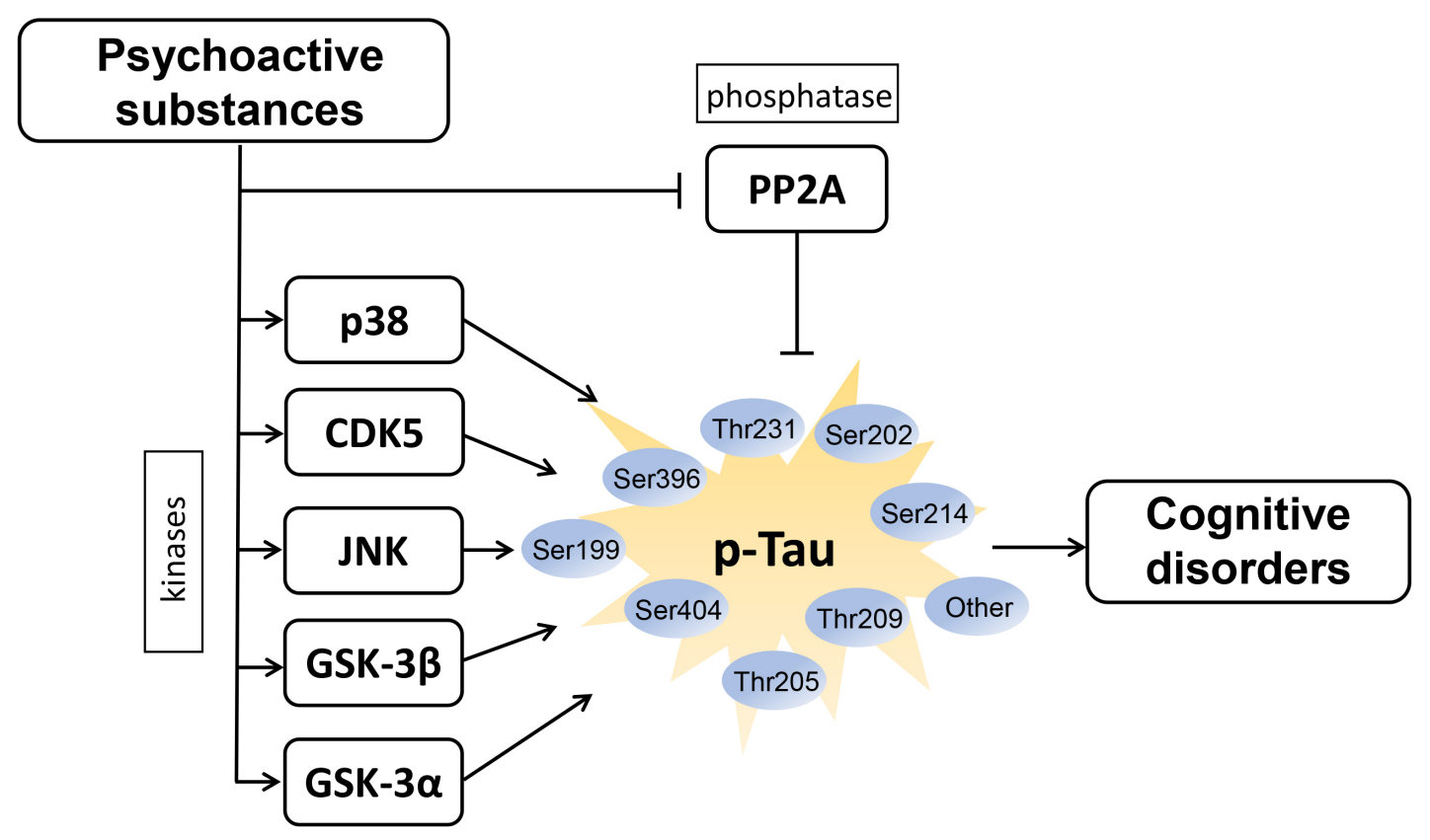

Fig. 4. Potential mechanism of psychoactive substances induced CDs. The overall mechanism could be summarized in "psychoactive substances-kinases/phosphatases-tau phosphorylation-CDs".

leaves contain over 25 alkaloids in which mitragynine and 7-hydroxymitragynine (7-HMG) are the primary active alkaloids in the plant. They are both indole-containing alkaloids. Mitragynine is suggested to 13 times more potent than morphine in regards to its opioid-like effects and 7-HMG is reported to be 4 times more powerful than mitragynine in its CNS stimulant effects [191]. In mice or rats, acute mitragynine independently led to impaired retrieval, memory consolidation and passive avoidance learning [192]. Chronic mitragynine administration impaired passive avoidance, object recognition learning [192], spatial learning [193], place learning, reversal learning [194] and memory [193,195].

Cathinone, naturally found in the Khat leaves, is a $\beta$-ketone amphetamine analogue and named (S)-2-amino-1-phenyl-1-propanone in organic chemistry nomenclature. Synthetic cathinones, including butylone, ethylone, mephedrone, methedrone, 3,4methylenedioxypyrovalerone (MDPV) and methylone are all derived from methcathinone [196,197]. Mephedrone impaired working memory [198], verbal learning, verbal fluency, cognitive flexibility [199] and spatial memory [200] in users. Research show that adult rats would show impairments in spatial memory and reversal learning after repeated mephedrone exposure in adolescence and mephedrone would induce more deleterious effects on cognition than amphetamine due to GluN2B-containing N-methyl-D-aspartate (NMDA) receptor dominance [201] while exposure to mephedrone during gestation induced an impairment of spatial learning and reference memory in offspring [202]. MDPV impaired novel object recognition function in a rat model of long-term voluntary bingelike self-administration [203]. Besides, MDPV caused widespread disruption of brain functional connectivity in rats which is linked to cognitive functions [204]. Several other studies in rodents also reported the CDs caused by synthetic cathinones [205-209].

\section{Perspective}

Overall, we demonstrated the potential role of tau protein in CDs induced by psychoactive substances. Abuse or inappropriate use of psychoactive substances could produce a variety of adverse reactions and social effects which highlights the importance of avoidance of drug abuse [2]. Cognitive function affects people's daily life, so it is of great significance to pay attention to the related mechanisms of CDs induced by psychoactive substances [6,210]. Many studies have shown that psychoactive substances can cause the phosphorylation of tau protein, and tau protein is closely associated with cognitive function. Both suggested that phosphorylated tau is involved in psychoactive substancesrelated CDs [211,212]. We summarized and proposed a potential mechanism of psychoactive substances induced CDs in Fig. 4. However, some experimental results, from the aspects of CDs and the sites of tau phosphorylation, show remarkable differences, which may be caused by different experimental environments, drug doses, treatment methods and time, and even individual differences. Moreover, the phosphorylation level of tau protein is regulated by the expression level or activity of related kinases, phosphatases, which makes related kinases and phosphatases the therapeutic targets on the pathway in turn $[67,68]$. Differ- 
ent psychoactive substances may act by affecting amounts and activities of different kinases and phosphatases in the metabolic pathway of tau protein; different psychoactive substances may cause hyper-phosphorylation of different sites of tau protein, both of which are worthy of further investigation to elucidate the specific mechanisms [19,213]. All of the above provide us with a new idea for treatment in psychoactive substances induced CDs and the application, which would have broad social benefits and clinical significance. Fortunately, many new kinds of drugs targeting the prevention of tau aggregation and denaturation, with the purpose of treating CDs like $\mathrm{AD}$, have been described in diverse studies with satisfactory results in recent years [214]. Nanotechnology also plays a promising role in tau-targeted pharmacotherapy because nanocarriers can improve the blood brain barrier (BBB) permeability of these new drugs [215].

In conclusion, psychoactive substances were primarily used in the clinical setting for therapeutic purposes. However, many people consume these compounds for different reasons, which may lead to CDs. Tauopathy is involved in psychoactive substance-induced CDs and different psychoactive substances may act by affecting the balance between kinases and/or phosphatases in the metabolic pathway of tau. However, the underlying mechanisms remain elusive in different conditions including different substances, different doses, different using terms or frequencies, different phosphorylation sites and different involved pathways. In the future, the specific role of tau in various psychoactive substances inducing CDs was warranted to be elucidated.

\section{Abbreviations}

ACEA, arachidonyl-2-chloroethylamid;

$\mathrm{AD}$, Alzheimer's Disease; AKT, protein kinase B; AMPA, $\alpha$-amino-3-hydroxy-5-methyl-4-isoxazole-propionic acid; AMPK, Adenosine Monophosphate Activated Protein Kinase; ASST, attentional set-shifting task; ATS, amphetamine-type stimulants; BBB, Blood Brain Barrier; CDK-5, Cyclin-dependent kinase-5; CDs, cognitive disorders; CNS, central nervous system; DBH, dopamine $\beta$-hydroxylase enzyme; DDAH1/ADMA/NOS, dimethylarginine dimethylaminohydrolase 1/asymmetric dimethylated L-arginine/Nitric Oxide Synthase; Dkk-1, Dickkopf-1; DSM-5, Diagnostic and Statistical Manual of Mental Disorder, Fifth Edition; ERK, extracellular regulated protein kinases; GSK-3 $\beta$, glycogen synthase kinase $3 \beta$; GSTP1, glutathione S-transferase P1; ICR, Institute of Cancer Research; iNOS, inducible nitric oxide synthase; IR, insulin receptor; IRS1, insulin receptor substrate-1; JNKs, c-Jun NH2-terminal kinases; MAPKs, Mitogen-activated protein kinases; MDMA, 3,4-methylenedioxymethamphetamine; METH, Methamphetamine; MoCA, Montreal Cognitive Assessment; MPTP, 1-methyl-4-phenyl-1,2,3,6-tetrahydropyridine;
MWM, Morris Water Maze; NFTs, neurofibrillary tangles; NORT, novel object recognition task; NPs, neuritic plaques; NPS, New Psychoactive Substances; PCP, phencyclidine; PHFs, paired helical filaments; PP2A, protein phosphatase 2A; PP2B, protein phosphatase $2 \mathrm{~B}$; PTSD, post-traumatic stress disorder; SCs, Synthetic cannabinoids; SD, Sprague-Dawley; SPMSQ, short portable mental status questionnaire; TBI, traumatic brain injury; Wnt, wingless-type MMTV integration site family; $\Delta$ 9-THC, $\Delta$ 9-tetrahydrocannabinol.

\section{Author contributions}

XW developed the idea. YYW, JCL, JNH reviewed the articles and wrote the manuscript. GHW revised and modified the manuscript. All authors approved the final version for publication.

\section{Ethics approval and consent to participate}

Not applicable.

\section{Acknowledgment}

Not applicable.

\section{Funding}

We are indebted to the participants for their dedication to this study. The present study was supported by grants from the National Natural Science Fund of China (81971794, 81671867).

\section{Conflict of interest}

The authors declare no conflict of interest.

\section{References}

[1] United Nations Office on Drugs and Crime. World Drug Report 2018. 2018. Available at: https://www.unodc.org/wdr2018/ (Accessed: 10 September 2021).

[2] Wohlfarth A, Weinmann W. Bioanalysis of new designer drugs. Bioanalysis. 2010; 2: 965-979.

[3] United Nations Office on Drugs and Crime. World Drug Report 2021. 2021. Available at: https://www.unodc.org/unodc/en/dat a-and-analysis/wdr2021.html (Accessed: 20 November 2021).

[4] Bruijnen CJWH, Dijkstra BAG, Walvoort SJW, Markus W, VanDerNagel JEL, Kessels RPC, et al. Prevalence of cognitive impairment in patients with substance use disorder. Drug and Alcohol Review. 2019; 38: 435-442.

[5] Hagen E, Sømhovd M, Hesse M, Arnevik EA, Erga AH. Measuring cognitive impairment in young adults with polysubstance use disorder with MoCA or BRIEF-a - the significance of psychiatric symptoms. Journal of Substance Abuse Treatment. 2019; 97: $21-27$.

[6] Wu L, Sun D. Meta-Analysis of Milk Consumption and the Risk of Cognitive Disorders. Nutrients. 2016; 8: 824

[7] Vik PW, Cellucci T, Jarchow A, Hedt J. Cognitive impairment in substance abuse. Psychiatric Clinics of North America. 2004; 27: 97-109.

[8] Kovacs GG. Invited review: Neuropathology of tauopathies: principles and practice. Neuropathology and Applied Neurobiology. 2015; 41: 3-23. 
[9] Orr ME, Sullivan AC, Frost B. A Brief Overview of Tauopathy: Causes, Consequences, and Therapeutic Strategies. Trends in Pharmacological Sciences. 2017; 38: 637-648.

[10] Tai H, Serrano-Pozo A, Hashimoto T, Frosch MP, Spires-Jones TL, Hyman BT. The Synaptic Accumulation of Hyperphosphorylated Tau Oligomers in Alzheimer Disease is Associated with Dysfunction of the Ubiquitin-Proteasome System. The American Journal of Pathology. 2012; 181: 1426-1435.

[11] Grundke-Iqbal I, Iqbal K, Quinlan M, Tung YC, Zaidi MS, Wisniewski HM. Microtubule-associated protein tau. a component of Alzheimer paired helical filaments. Journal of Biological Chemistry. 1986; 261: 6084-6089.

[12] Bejanin A, Schonhaut DR, La Joie R, Kramer JH, Baker SL, Sosa N, et al. Tau pathology and neurodegeneration contribute to cognitive impairment in Alzheimer's disease. Brain. 2017; 140: 3286-3300.

[13] Wang J, Xia Y, Grundke-Iqbal I, Iqbal K. Abnormal Hyperphosphorylation of Tau: Sites, Regulation, and Molecular Mechanism of Neurofibrillary Degeneration. Journal of Alzheimer's Disease. 2013; 33: S123-S139.

[14] Martin L, Latypova X, Wilson CM, Magnaudeix A, Perrin M, Yardin C, et al. Tau protein kinases: Involvement in Alzheimer's disease. Ageing Research Reviews. 2013; 12: 289-309.

[15] Martin L, Latypova X, Wilson CM, Magnaudeix A, Perrin M, Terro F. Tau protein phosphatases in Alzheimer's disease: the leading role of PP2a. Ageing Research Reviews. 2013; 12: 3949.

[16] Hector A, McAnulty C, Piché-Lemieux M, Alves-Pires C, BuéeScherrer V, Buée L, et al. Tau hyperphosphorylation induced by the anesthetic agent ketamine/xylazine involved the calmodulindependent protein kinase II. The FASEB Journal. 2020; 34: 2968-2977.

[17] Li Y, Wen G, Ding R, Ren X, Jing C, Liu L, et al. Effects of Single-Dose and Long-Term Ketamine Administration on Tau Phosphorylation-Related Enzymes GSK-3beta, CDK5, PP2A, and PP2B in the Mouse Hippocampus. Journal of Molecular Neuroscience. 2020; 70: 2068-2076.

[18] Panmak P, Nopparat C, Permpoonpattana K, Namyen J, Govitrapong P. Melatonin protects against methamphetamineinduced Alzheimer's disease-like pathological changes in rat hippocampus. Neurochemistry International. 2021; 148: 105121.

[19] Wang Y, Mandelkow E. Tau in physiology and pathology. Nature Reviews Neuroscience. 2016; 17: 5-21.

[20] Di J, Cohen LS, Corbo CP, Phillips GR, El Idrissi A, Alonso AD. Abnormal tau induces cognitive impairment through two different mechanisms: synaptic dysfunction and neuronal loss. Scientific Reports. 2016; 6: 20833.

[21] Mattsson N, Scholl M, Strandberg O, Smith R, Palmqvist S, Insel PS, et al. 18F-AV-1451 and CSF T-tau and P-tau as biomarkers in Alzheimer's disease. EMBO Molecular Medicine. 2017; 9: 1212-1223.

[22] Olsson B, Lautner R, Andreasson U, Öhrfelt A, Portelius E, Bjerke $\mathrm{M}$, et al. CSF and blood biomarkers for the diagnosis of Alzheimer's disease: a systematic review and meta-analysis. The Lancet Neurology. 2016; 15: 673-684.

[23] Chhatwal JP, Schultz AP, Dang Y, Ostaszewski B, Liu L, Yang $\mathrm{H}$, et al. Plasma $N$-terminal tau fragment levels predict future cognitive decline and neurodegeneration in healthy elderly individuals. Nature Communications. 2020; 11: 6024.

[24] Trescot AM, Datta S Fau-Lee M, Lee M Fau-Hansen H, Hansen H. Opioid pharmacology. Pain Physician. 2008; 11: S133-S153.

[25] Ghelardini C, Di Cesare Mannelli L, Bianchi E. The pharmacological basis of opioids. Clinical Cases in Mineral and Bone Metabolism. 2015; 12: 219-221.

[26] Christrup LL. Morphine metabolites. Acta Anaesthesiologica
Scandinavica. 1997; 41: 116-122.

[27] Ersche KD, Clark L, London M, Robbins TW, Sahakian BJ. Profile of Executive and Memory Function Associated with Amphetamine and Opiate Dependence. Neuropsychopharmacology. 2006; 31: 1036-1047.

[28] Rapeli P, Fabritius C, Kalska H, Alho H. Cognitive functioning in opioid-dependent patients treated with buprenorphine, methadone, and other psychoactive medications: stability and correlates. BMC Clinical Pharmacology. 2011; 11: 13.

[29] Soyka M, Lieb M, Kagerer S, Zingg C, Koller G, Lehnert P, et al. Cognitive Functioning during Methadone and Buprenorphine Treatment. Journal of Clinical Psychopharmacology. 2008; 28: 699-703.

[30] Prosser J, London ED, Galynker II. Sustained attention in patients receiving and abstinent following methadone maintenance treatment for opiate dependence: Performance and neuroimaging results. Drug and Alcohol Dependence. 2009; 104: 228-240.

[31] Friswell J, Phillips C, Holding J, Morgan CJA, Brandner B, Curran HV. Acute effects of opioids on memory functions of healthy men and women. Psychopharmacology. 2008; 198: 243-250.

[32] Naghibi SM, Hosseini M, Khani F, Rahimi M, Vafaee F, Rakhshandeh $\mathrm{H}$, et al. Effect of Aqueous Extract ofCrocus sativusL. on Morphine-Induced Memory Impairment. Advances in Pharmacological Sciences. 2012; 2012: 1-7.

[33] Baiamonte BA, Lee FA, Gould HJ, Soignier RD. MorphineInduced Cognitive Impairment Is Attenuated by Induced Pain in Rats. Behavioral Neuroscience. 2013; 127: 524-534.

[34] Hasanein P, Ghafari-Vahed M. Fatty acid amide hydrolase inhibitor URB597 prevented tolerance and cognitive deficits induced by chronic morphine administration in rats. Behavioural Pharmacology. 2016; 27: 37-43.

[35] Alaei H, Borjeian L, Azizi M, Orian S, Pourshanazari A, Hanninen $\mathrm{O}$. Treadmill running reverses retention deficit induced by morphine. European Journal of Pharmacology. 2006; 536: 138141.

[36] Adedayo AD, Aderinola AA, Adekilekun TA, Olaolu OO, Olanike AM, Olayemi IK. Morphine-alcohol treatment impairs cognitive functions and increases neuro-inflammatory responses in the medial prefrontal cortex of juvenile male rats. Anatomy \& Cell Biology. 2018; 51: 41-51.

[37] Miladi-Gorji H, Rashidy-Pour A, Fathollahi Y, Akhavan MM, Semnanian S, Safari M. Voluntary exercise ameliorates cognitive deficits in morphine dependent rats: the role of hippocampal brain-derived neurotrophic factor. Neurobiology of Learning and Memory. 2011; 96: 479-491.

[38] Ghodrati-Jaldbakhan S, Ahmadalipour A, Rashidy-Pour A, Vafaei AA, Miladi-Gorji H, Alizadeh M. Low- and highintensity treadmill exercise attenuates chronic morphineinduced anxiogenesis and memory impairment but not reductions in hippocampal BDNF in female rats. Brain Research. 2017; 1663: 20-28.

[39] Wang Y, Yin F, Guo H, Zhang J, Yan P, Lai J. The Role of Dopamine D1 and D3 Receptors in $N$-Methyl-D-Aspartate (NMDA)/GlycineB Site-Regulated Complex Cognitive Behaviors following Repeated Morphine Administration. International Journal of Neuropsychopharmacology. 2017; 20: 562-574.

[40] Flanagan ME, Larson EB, Walker RL, Keene CD, Postupna N, Cholerton B, et al. Associations between Use of Specific Analgesics and Concentrations of Amyloid-beta 42 or Phospho-Tau in Regions of Human Cerebral Cortex. Journal of Alzheimer's Disease. 2018; 61: 653-662.

[41] Ramage SN, Anthony IC, Carnie FW, Busuttil A, Robertson R, Bell JE. Hyperphosphorylated tau and amyloid precursor protein deposition is increased in the brains of young drug abusers. Neuropathology and Applied Neurobiology. 2005; 31: 439-448.

[42] Nakano H, Kobayashi K, Sugimori K, Shimazaki M, Miyazu 
K, Hayashi M, et al. Regional Analysis of Differently Phosphorylated Tau Proteins in Brains from Patients with Alzheimer's Disease. Dementia and Geriatric Cognitive Disorders. 2004; 17: 122-131.

[43] Anthony IC, Norrby KE, Dingwall T, Carnie FW, Millar T, Arango JC, et al. Predisposition to accelerated Alzheimerrelated changes in the brains of human immunodeficiency virus negative opiate abusers. Brain. 2010; 133: 3685-3698.

[44] Cao M, Liu F, Ji F, Liang J, Liu L, Wu Q, et al. Effect of c-Jun $\mathrm{N}$-terminal kinase $(\mathrm{JNK}) / \mathrm{p} 38$ mitogen-activated protein kinase (p38 MAPK) in morphine-induced tau protein hyperphosphorylation. Behavioural Brain Research. 2013; 237: 249-255.

[45] Xia B, Li Y, Li R, Yin D, Chen X, Li J, et al. Effect of Sirtuin-1 on Synaptic Plasticity in Nucleus Accumbens in a Rat Model of Heroin Addiction. Medical Science Monitor. 2018; 24: 37893803.

[46] Liu Q, Zhang P, Zhen Q, Walther D, Wang X, Uhl GR. KEPI, a PKC-dependent Protein Phosphatase 1 Inhibitor Regulated by Morphine. Journal of Biological Chemistry. 2002; 277: 1331213320.

[47] Xu J, Tian W, Ma X, Guo J, Shi Q, Jin Y, et al. The Molecular Mechanism Underlying Morphine-Induced Akt Activation: Roles of Protein Phosphatases and Reactive Oxygen Species. Cell Biochemistry and Biophysics. 2011; 61: 303-311.

[48] Park H, Lee K, Oh S, Yan R, Zhang J, Beach TG, et al. Protein Phosphatase 2a and its Methylation Modulating Enzymes LCMT-1 and PME-1 are Dysregulated in Tauopathies of Progressive Supranuclear Palsy and Alzheimer Disease. Journal of Neuropathology \& Experimental Neurology. 2018; 77: 139148.

[49] Kovacs GG, Horvath MC, Majtenyi K, Lutz MI, Hurd YL, Keller E. Heroin abuse exaggerates age-related deposition of hyperphosphorylated tau and p62-positive inclusions. Neurobiology of Aging. 2015; 36: 3100-3107.

[50] Carvalho M, Carmo H, Costa VM, Capela JP, Pontes H, Remião F, et al. Toxicity of amphetamines: an update. Archives of Toxicology. 2012; 86: 1167-1231.

[51] Curran HV. Is MDMA ('Ecstasy') Neurotoxic in Humans? an Overview of Evidence and of Methodological Problems in Research. Neuropsychobiology. 2000; 42: 34-41.

[52] Sarkar S, Schmued L. Neurotoxicity of Ecstasy (MDMA): an Overview. Current Pharmaceutical Biotechnology. 2010; 11: 460-469.

[53] Cole JC. MDMA and the "Ecstasy Paradigm". Journal of Psychoactive Drugs. 2014; 46: 44-56.

[54] Meyer JS. 3, 4-methylenedioxymethamphetamine (MDMA): current perspectives. Substance Abuse and Rehabilitation. 2013; 4: 83-99.

[55] Sessa B. MDMA and PTSD treatment: From novel pathophysiology to innovative therapeutics. Neuroscience Letters. 2017; 649: $176-180$.

[56] Wunderli MD, Vonmoos M, Fürst M, Schädelin K, Kraemer T, Baumgartner MR, et al. Discrete memory impairments in largely pure chronic users of MDMA. European Neuropsychopharmacology. 2017; 27: 987-999.

[57] Wunderli MD, Vonmoos M, Treichler L, Zeller C, Dziobek I, Kraemer T, et al. Social Cognition and Interaction in Chronic Users of 3,4-Methylenedioxymethamphetamine (MDMA, "Ecstasy"). International Journal of Neuropsychopharmacology. 2018; 21: 333-344.

[58] Potter A, Downey L, Stough C. Cognitive Function in Ecstasy Naive Abstinent Drug Dependants and MDMA Users. Current Drug Abuse Reviews. 2013; 6: 71-76.

[59] Taghizadeh G, Pourahmad J, Mehdizadeh H, Foroumadi A, Torkaman-Boutorabi A, Hassani S, et al. Protective effects of physical exercise on MDMA-induced cognitive and mitochon- drial impairment. Free Radical Biology and Medicine. 2016; 99 : $11-19$.

[60] Viñals X, Maldonado R, Robledo P. Effects of repeated treatment with MDMA on working memory and behavioural flexibility in mice. Addiction Biology. 2013; 18: 263-273.

[61] Costa G, Simola N, Morelli M. MDMA administration during adolescence exacerbates MPTP-induced cognitive impairment and neuroinflammation in the hippocampus and prefrontal cortex. Psychopharmacology. 2014; 231: 4007-4018.

[62] García-Pardo MP, Roger-Sánchez C, Rodríguez-Arias M, Miñarro J, Aguilar MA. Cognitive and behavioural effects induced by social stress plus MDMA administration in mice. Behavioural Brain Research. 2017; 319: 63-72.

[63] Barbosa DJ, Serrat R, Mirra S, Quevedo M, Gómez de Barreda $\mathrm{E}$, Ávila $\mathrm{J}$, et al. MDMA impairs mitochondrial neuronal trafficking in a Tau- and Mitofusin2/Drp1-dependent manner. Archives of Toxicology. 2014; 88: 1561-1572.

[64] Kandimalla R, Manczak M, Yin X, Wang R, Reddy PH. Hippocampal phosphorylated tau induced cognitive decline, dendritic spine loss and mitochondrial abnormalities in a mouse model of Alzheimer's disease. Human Molecular Genetics. 2018; 27: 30-40.

[65] Busceti CL, Biagioni F, Riozzi B, Battaglia G, Storto M, Cinque $\mathrm{C}$, et al. Enhanced Tau Phosphorylation in the Hippocampus of Mice Treated with 3,4-Methylenedioxymethamphetamine ("Ecstasy"). Journal of Neuroscience. 2008; 28: 3234-3245.

[66] Gruart A, Munoz MD, Delgado-Garcia JM. Involvement of the CA3-CA1 Synapse in the Acquisition of Associative Learning in Behaving Mice. Journal of Neuroscience. 2006; 26: 1077-1087.

[67] Abad S, Ramon-Duaso C, López-Arnau R, Folch J, Pubill D, Camarasa J, et al. Effects of MDMA on neuroplasticity, amyloid burden and phospho-tau expression in APPswe/PS1dE9 mice. Journal of Psychopharmacology. 2019; 33: 1170-1182.

[68] Feio-Azevedo R, Costa VM, Barbosa DJ, Teixeira-Gomes A, Pita I, Gomes S, et al. Aged rats are more vulnerable than adolescents to "ecstasy"-induced toxicity. Archives of Toxicology. 2018; 92: 2275-2295.

[69] Yu S, Zhu L, Shen Q, Bai X, Di X. Recent Advances in Methamphetamine Neurotoxicity Mechanisms and its Molecular Pathophysiology. Behavioural Neurology. 2015; 2015: 103969.

[70] Courtney KE, Ray LA. Methamphetamine: an update on epidemiology, pharmacology, clinical phenomenology, and treatment literature. Drug and Alcohol Dependence. 2014; 143: 1121.

[71] Krasnova IN, Cadet JL. Methamphetamine toxicity and messengers of death. Brain Research Reviews. 2009; 60: 379-407.

[72] Soltanian B, Dehghan Shasaltaneh M, Riazi GH, Masoudian N. Alteration of gene expression in reactive astrocytes induced by a $\beta 1-42$ using low dose of methamphetamine. Molecular Biology Reports. 2021; 48: 6103-6112.

[73] Rau T, Ziemniak J, Poulsen D. The neuroprotective potential of low-dose methamphetamine in preclinical models of stroke and traumatic brain injury. Progress in Neuro-Psychopharmacology and Biological Psychiatry. 2016; 64: 231-236.

[74] Wang T, Fan T, Bao Y, Li X, Liang C, Wang R, et al. Pattern and related factors of cognitive impairment among chronic methamphetamine users. The American Journal on Addictions. 2017; 26: $145-151$.

[75] Dean AC, Morales AM, Hellemann G, London ED. Cognitive deficit in methamphetamine users relative to childhood academic performance: link to cortical thickness. Neuropsychopharmacology. 2018; 43: 1745-1752.

[76] Potvin S, Pelletier J, Grot S, Hébert C, Barr AM, Lecomte T. Cognitive deficits in individuals with methamphetamine use disorder: a meta-analysis. Addictive Behaviors. 2018; 80: 154 160. 
[77] Kwiatkowski MA, Donald KA, Stein DJ, Ipser J, Thomas KGF, Roos A. Cognitive outcomes in prenatal methamphetamine exposed children aged six to seven years. Comprehensive Psychiatry. 2018; 80: 24-33.

[78] Zhang K, Zhang Q, Jiang H, Du J, Zhou C, Yu S, et al. Impact of aerobic exercise on cognitive impairment and oxidative stress markers in methamphetamine-dependent patients. Psychiatry Research. 2018; 266: 328-333.

[79] Cox BM, Cope ZA, Parsegian A, Floresco SB, Aston-Jones G, See RE. Chronic methamphetamine self-administration alters cognitive flexibility in male rats. Psychopharmacology. 2016; 233: 2319-2327.

[80] Thanos PK, Kim R, Delis F, Rocco MJ, Cho J, Volkow ND. Effects of chronic methamphetamine on psychomotor and cognitive functions and dopamine signaling in the brain. Behavioural Brain Research. 2017; 320: 282-290.

[81] González B, Jayanthi S, Gomez N, Torres OV, Sosa MH, Bernardi $\mathrm{A}$, et al. Repeated methamphetamine and modafinil induce differential cognitive effects and specific histone acetylation and DNA methylation profiles in the mouse medial prefrontal cortex. Progress in Neuro-Psychopharmacology and Biological Psychiatry. 2018; 82: 1-11.

[82] Seyedhosseini Tamijani SM, Beirami E, Ahmadiani A, Dargahi L. Effect of three different regimens of repeated methamphetamine on rats' cognitive performance. Cognitive Processing. 2018; 19: 107-115.

[83] Beirami E, Oryan S, Seyedhosseini Tamijani SM, Ahmadiani A, Dargahi L. Intranasal insulin treatment restores cognitive deficits and insulin signaling impairment induced by repeated methamphetamine exposure. Journal of Cellular Biochemistry. 2018; 119: 2345-2355.

[84] Xu H, Chen X, Wang J, Yang T, Liu N, Cheng J, et al. Involvement of insulin signalling pathway in methamphetamineinduced hyperphosphorylation of Tau. Toxicology. 2018; 408: 88-94.

[85] Li L, Chen S, Wang Y, Yue X, Xu J, Xie W, et al. Role of GSK3beta/alpha-synuclein axis in methamphetamine-induced neurotoxicity in PC12 cells. Toxicology Research. 2017; 7: 221-234.

[86] Chen L, Zhou L, Yu P, Fang F, Jiang L, Fei J, et al. Methamphetamine exposure upregulates the amyloid precursor protein and hyperphosphorylated tau expression: the roles of insulin signaling in SH-SY5Y cell line. The Journal of Toxicological Sciences. 2019; 44: 493-503.

[87] Ding J, Lian Y, Meng Y, He Y, Fan H, Li C, et al. The effect of alpha-synuclein and Tau in methamphetamine induced neurotoxicity in vivo and in vitro. Toxicology Letters. 2020; 319: 213-224.

[88] Ding J, Hu S, Meng Y, Li C, Huang J, He Y, et al. AlphaSynuclein deficiency ameliorates chronic methamphetamine induced neurodegeneration in mice. Toxicology. 2020; 438: 152461.

[89] Dong H, Huang Z, Zhang H, Xiao Z, Liu Q. Rs13293512 polymorphism located in the promoter region of let-7 is associated with increased risk of radiation enteritis in colorectal cancer. Journal of Cellular Biochemistry. 2018; 119: 6535-6544.

[90] Zhang F, Chen L, Liu C, Qiu P, Wang A, Li L, et al. Upregulation of protein tyrosine nitration in methamphetamineinduced neurotoxicity through DDAH/ADMA/NOS pathway. Neurochemistry International. 2013; 62: 1055-1064.

[91] Chen P, Chen J. Enhanced Cdk5 Activity and p35 Translocation in the Ventral Striatum of Acute and Chronic MethamphetamineTreated Rats. Neuropsychopharmacology. 2005; 30: 538-549.

[92] Gkioka E, Korou LM, Daskalopoulou A, Misitzi A, Batsidis E, Bakoyiannis I, et al. Prenatal cocaine exposure and its impact on cognitive functions of offspring: a pathophysiological insight.
Reviews in the Neurosciences. 2016; 27: 523-534.

[93] Treadwell SD, Robinson TG. Cocaine use and stroke. Postgraduate Medical Journal. 2007; 83: 389-394.

[94] Pomara C, Cassano T, D'Errico S, Bello S, Romano AD, Riezzo I, et al. Data Available on the Extent of Cocaine Use and Dependence: Biochemistry, Pharmacologic Effects and Global Burden of Disease of Cocaine Abusers. Current Medicinal Chemistry. 2012; 19: 5647-5657.

[95] Pendergraft WF, Herlitz LC, Thornley-Brown D, Rosner M, Niles JL. Nephrotoxic Effects of Common and Emerging Drugs of Abuse. Clinical Journal of the American Society of Nephrology. 2014; 9: 1996-2005.

[96] Dwyer C, Sowerby L, Rotenberg BW. Is cocaine a safe topical agent for use during endoscopic sinus surgery? The Laryngoscope. 2016; 126: 1721-1723.

[97] Maraj S, Figueredo VM, Lynn Morris D. Cocaine and the Heart. Clinical Cardiology. 2010; 33: 264-269.

[98] Kloner RA, Hale S. Unraveling the complex effects of cocaine on the heart. Circulation. 1993; 87: 1046-1047.

[99] Kilbey M, Breslau N, Andreski P. Cocaine use and dependence in young adults: associated psychiatric disorders and personality traits. Drug and Alcohol Dependence. 1992; 29: 283-290.

[100] Degenhardt L, Hall W. Extent of illicit drug use and dependence, and their contribution to the global burden of disease. The Lancet. 2012; 379: 55-70.

[101] Nutt D, King LA, Saulsbury W, Blakemore C. Development of a rational scale to assess the harm of drugs of potential misuse. The Lancet. 2007; 369: 1047-1053.

[102] Spronk DB, van Wel JHP, Ramaekers JG, Verkes RJ. Characterizing the cognitive effects of cocaine: a comprehensive review. Neuroscience \& Biobehavioral Reviews. 2013; 37: 1838 1859.

[103] Fillmore MT, Rush CR, Hays L. Acute effects of cocaine in two models of inhibitory control: implications of non-linear dose effects. Addiction. 2006; 101: 1323-1332.

[104] Higgins ST, Rush CR, Bickel WK, Hughes JR, Lynn M, Capeless MA. Acute behavioral and cardiac effects of cocaine and alcohol combinations in humans. Psychopharmacology. 1993; 111: 285-294.

[105] Ramaekers JG, van Wel JH, Spronk D, Franke B, Kenis G, Toennes SW, et al. Cannabis and cocaine decrease cognitive impulse control and functional corticostriatal connectivity in drug users with low activity DBH genotypes. Brain Imaging and Behavior. 2016; 10: 1254-1263.

[106] Soar K, Mason C, Potton A, Dawkins L. Neuropsychological effects associated with recreational cocaine use. Psychopharmacology. 2012; 222: 633-643.

[107] Potvin S, Stavro K, Rizkallah E, Pelletier J. Cocaine and Cognition. Journal of Addiction Medicine. 2014; 8: 368-376.

[108] Almeida PP, de Araujo Filho GM, Malta SM, Laranjeira RR, Marques ACRP, Bressan RA, et al. Attention and memory deficits in crack-cocaine users persist over four weeks of abstinence. Journal of Substance Abuse Treatment. 2017; 81: 73-78.

[109] van der Plas EAA, Crone EA, van den Wildenberg WPM, Tranel D, Bechara A. Executive control deficits in substancedependent individuals: a comparison of alcohol, cocaine, and methamphetamine and of men and women. Journal of Clinical and Experimental Neuropsychology. 2009; 31: 706-719.

[110] Vonmoos M, Hulka LM, Preller KH, Minder F, Baumgartner MR, Quednow BB. Cognitive Impairment in Cocaine Users is Drug-Induced but Partially Reversible: Evidence from a Longitudinal Study. Neuropsychopharmacology. 2014; 39: 22002210.

[111] DiGirolamo GJ, Gonzalez G, Smelson D, Guevremont N, Andre MI, Patnaik PO, et al. Increased Depression and Anxiety Symptoms are Associated with more Breakdowns in Cognitive 
Control to Cocaine Cues in Veterans with Cocaine Use Disorder. Journal of Dual Diagnosis. 2017; 13: 298-304.

[112] Dackis CA, O'Brien CP. Cocaine dependence: a disease of the brain's reward centers. Journal of Substance Abuse Treatment. 2001; 21: 111-117.

[113] Goldstein RZ, Woicik PA, Lukasik T, Maloney T, Volkow ND. Drug fluency: a potential marker for cocaine use disorders. Drug and Alcohol Dependence. 2007; 89: 97-101.

[114] Melamed JL, de Jesus FM, Aquino J, Vannuchi CRS, Duarte RBM, Maior RS, et al. Differential modulatory effects of cocaine on marmoset monkey recognition memory. Progress in Brain Research. 2017; 235: 155-176.

[115] Kromrey SA, Gould RW, Nader MA, Czoty PW. Effects of prior cocaine self-administration on cognitive performance in female cynomolgus monkeys. Psychopharmacology. 2015; 232: 2007-2016.

[116] Liu SJ, Fang ZY, Yang Y, Deng HM, Wang JZ. Alzheimer-like phosphorylation of tau and neurofilament induced by cocaine in vivo. Acta Pharmacologica Sinica. 2003; 24: 512-518.

[117] Lew GM. Microtubular tau protein after cocaine in cultured SH-SY5Y human neuroblastoma. General Pharmacology. 1992; 23: $1111-1113$

[118] Zanos P, Moaddel R, Morris PJ, Riggs LM, Highland JN, Georgiou $\mathrm{P}$, et al. Ketamine and Ketamine Metabolite Pharmacology: Insights into Therapeutic Mechanisms. Pharmacological Reviews. 2018; 70: 621-660.

[119] Quibell R, Fallon M, Mihalyo M, Twycross R, Wilcock A. Ketamine. Journal of Pain and Symptom Management. 2015; 50: 268-278.

[120] Domino EF, Warner DS. Taming the Ketamine Tiger. Anesthesiology. 2010; 113: 678-684.

[121] Peltoniemi MA, Hagelberg NM, Olkkola KT, Saari TI. Ketamine: a Review of Clinical Pharmacokinetics and Pharmacodynamics in Anesthesia and Pain Therapy. Clinical Pharmacokinetics. 2016; 55: 1059-1077.

[122] Coyle CM, Laws KR. The use of ketamine as an antidepressant: a systematic review and meta-analysis. Human Psychopharmacology. 2015; 30: 152-163.

[123] Jansen KL, Darracot-Cankovic R. The nonmedical use of ketamine, part two: A review of problem use and dependence. Journal of Psychoactive Drugs. 2001; 33: 151-158.

[124] United Nations Office on Drugs and Crime. World Drug Report 2017. 2017. Available at: https://www.unodc.org/wdr2017/inde x.html (Accessed: 10 September 2021).

[125] Kim M, Cho S, Lee J. The Effects of Long-Term Ketamine Treatment on Cognitive Function in Complex Regional Pain Syndrome: a Preliminary Study. Pain Medicine. 2016; 17: $1447-1451$

[126] Rascón-Martínez DM, Fresán-Orellana A, Ocharán-Hernández ME, Genis-Zarate JH, Castellanos-Olivares A. The Effects of Ketamine on Cognitive Function in Elderly Patients Undergoing Ophthalmic Surgery: A Pilot Study. Anesthesia \& Analgesia. 2016; 122: 969-975.

[127] D'Souza DC, Ahn K, Bhakta S, Elander J, Singh N, Nadim H, et al. Nicotine Fails to Attenuate Ketamine-Induced Cognitive Deficits and Negative and Positive Symptoms in Humans: Implications for Schizophrenia. Biological Psychiatry. 2012; 72: 785-794.

[128] Ranganathan M, DeMartinis N, Huguenel B, Gaudreault F, Bednar MM, Shaffer CL, et al. Attenuation of ketamine-induced impairment in verbal learning and memory in healthy volunteers by the AMPA receptor potentiator PF-04958242. Molecular Psychiatry. 2017; 22: 1633-1640.

[129] Gao Y, Xiao F, Wang C, Wang C, Cui P, Zhang X, et al. Long noncoding RNA MALAT1 promotes osterix expression to regulate osteogenic differentiation by targeting miRNA-143 in hu- man bone marrow-derived mesenchymal stem cells. Journal of Cellular Biochemistry. 2018; 119: 6986-6996.

[130] Ke X, Ding Y, Xu K, He H, Wang D, Deng X, et al. The profile of cognitive impairments in chronic ketamine users. Psychiatry Research. 2018; 266: 124-131.

[131] Wang L, Chen C, Lin S, Chen Y, Xu K, Huang M. Cognitive profile of ketamine-dependent patients compared with methamphetamine-dependent patients and healthy controls. Psychopharmacology. 2018; 235: 2113-2121.

[132] Liao Y, Tang J, Ma M, Wu Z, Yang M, Wang X, et al. Frontal white matter abnormalities following chronic ketamine use: a diffusion tensor imaging study. Brain. 2010; 133: 2115-2122.

[133] Nikiforuk A, Hołuj M, Kos T, Popik P. The effects of a 5-HT5a receptor antagonist in a ketamine-based rat model of cognitive dysfunction and the negative symptoms of schizophrenia. Neuropharmacology. 2016; 105: 351-360.

[134] Zhao T, Li Y, Wei W, Savage S, Zhou L, Ma D. Ketamine administered to pregnant rats in the second trimester causes longlasting behavioral disorders in offspring. Neurobiology of Disease. 2014; 68: 145-155.

[135] Li Y, Li X, Guo C, Li L, Wang Y, Zhang Y, et al. Long-term neurocognitive dysfunction in offspring via NGF/ERK/CREB signaling pathway caused by ketamine exposure during the second trimester of pregnancy in rats. Oncotarget. 2017; 8: 3095630970.

[136] Phensy A, Duzdabanian HE, Brewer S, Panjabi A, Driskill C, Berz A, et al. Antioxidant Treatment with $N$-acetyl Cysteine Prevents the Development of Cognitive and Social Behavioral Deficits that Result from Perinatal Ketamine Treatment. Frontiers in Behavioral Neuroscience. 2017; 11: 106.

[137] Ding R, Li Y, Du A, Yu H, He B, Shen R, et al. Changes in hippocampal AMPA receptors and cognitive impairments in chronic ketamine addiction models: another understanding of ketamine CNS toxicity. Scientific Reports. 2016; 6: 38771.

[138] Li Y, Shen R, Wen G, Ding R, Du A, Zhou J, et al. Effects of Ketamine on Levels of Inflammatory Cytokines IL-6, IL-1beta, and TNF-alpha in the Hippocampus of Mice Following Acute or Chronic Administration. Frontiers in Pharmacology. 2017; 8: 139.

[139] Tan S, Rudd JA, Yew DT. Gene expression changes in GABA (A) receptors and cognition following chronic ketamine administration in mice. PLoS ONE. 2011; 6: e21328.

[140] Huang S, Dai Y, Zhang Z, Hao W, Chen H. Docosahexaenoic acid intake ameliorates ketamine-induced impairment of spatial cognition and learning ability in ICR mice. Neuroscience Letters. 2014; 580: 125-129.

[141] Li Y, Ding R, Ren X, Wen G, Dong Z, Yao H, et al. Longterm ketamine administration causes Tau protein phosphorylation and Tau protein-dependent AMPA receptor reduction in the hippocampus of mice. Toxicology Letters. 2019; 315: 107-115.

[142] Yeung LY, Wai MSM, Fan M, Mak YT, Lam WP, Li Z, et $a l$. Hyperphosphorylated tau in the brains of mice and monkeys with long-term administration of ketamine. Toxicology Letters. 2010; 193: 189-193.

[143] Jin H, Hu Z, Dong M, Wu Y, Zhu Z, Xu L. Ketamine induces tau hyperphosphorylation at serine 404 in the hippocampus of neonatal rats. Neural Regeneration Research. 2013; 8: 1590 1596.

[144] Hector A, McAnulty C, Piché-Lemieux M, Alves-Pires C, Buée-Scherrer V, Buée L, et al. Tau hyperphosphorylation induced by the anesthetic agent ketaminexylazine involved the calmodulin-dependent protein kinase II. The FASEB Journal. 2020; 34: 2968-2977.

[145] Trecki J, Gerona RR, Schwartz MD. Synthetic CannabinoidRelated Illnesses and Deaths. New England Journal of Medicine. 2015; 373: 103-107. 
[146] Wiley JL, Marusich JA, Huffman JW, Balster RL, Thomas BF. Hijacking of Basic Research: The Case of Synthetic Cannabinoids. Methods Report RTI Press. 2011; 2011: 17971.

[147] Carroll FI, Lewin AH, Mascarella SW, Seltzman HH, Reddy PA. Designer drugs: a medicinal chemistry perspective. Annals of the New York Academy of Sciences. 2012; 1248: 18-38.

[148] Schifano F, Orsolini L, Duccio Papanti G, Corkery JM. Novel psychoactive substances of interest for psychiatry. World Psychiatry. 2015; 14: 15-26.

[149] Alves VL, Gonçalves JL, Aguiar J, Teixeira HM, Câmara JS. The synthetic cannabinoids phenomenon: from structure to toxicological properties. a review. Critical Reviews in Toxicology. 2020; 50: 359-382.

[150] White CM. The Pharmacologic and Clinical Effects of Illicit Synthetic Cannabinoids. The Journal of Clinical Pharmacology. 2017; 57: 297-304.

[151] Pintori N, Loi B, Mereu M. Synthetic cannabinoids: the hidden side of Spice drugs. Behavioural Pharmacology. 2017; 28: 409419.

[152] Patil KR, Goyal SN, Sharma C, Patil CR, Ojha S. Phytocannabinoids for Cancer Therapeutics: Recent Updates and $\mathrm{Fu}-$ ture Prospects. Current Medicinal Chemistry. 2015; 22: 34723501.

[153] Martinotti G, Santacroce R, Papanti D, Elgharably Y, Prilutskaya M, Corazza O. Synthetic Cannabinoids: Psychopharmacology, Clinical Aspects, Psychotic Onset. CNS \& Neurological Disorders Drug Targets. 2017; 16: 567-575.

[154] Schwartz MD, Trecki J, Edison LA, Steck AR, Arnold JK, Gerona RR. A Common Source Outbreak of Severe Delirium Associated with Exposure to the Novel Synthetic Cannabinoid ADB-PINACA. The Journal of Emergency Medicine. 2015; 48: 573-580.

[155] Wilkinson ST, Radhakrishnan R, D'Souza DC. Impact of Cannabis Use on the Development of Psychotic Disorders. Current Addiction Reports. 2014; 1: 115-128.

[156] Musshoff F, Madea B, Kernbach-Wighton G, Bicker W, Kneisel S, Hutter M, et al. Driving under the influence of synthetic cannabinoids ("Spice"): a case series. International Journal of Legal Medicine. 2014; 128: 59-64.

[157] Cohen K, Kapitány-Fövény M, Mama Y, Arieli M, Rosca P, Demetrovics Z, et al. The effects of synthetic cannabinoids on executive function. Psychopharmacology. 2017; 234: 11211134.

[158] Castaneto MS, Gorelick DA, Desrosiers NA, Hartman RL, Pirard S, Huestis MA. Synthetic cannabinoids: Epidemiology, pharmacodynamics, and clinical implications. Drug and Alcohol Dependence. 2014; 144: 12-41.

[159] Ossato A, Canazza I, Trapella C, Vincenzi F, De Luca MA, Rimondo C, et al. Effect of JWH-250, JWH-073 and their interaction on "tetrad", sensorimotor, neurological and neurochemical responses in mice. Progress in Neuro-Psychopharmacology and Biological Psychiatry. 2016; 67: 31-50.

[160] Mills B, Yepes A, Nugent K. Synthetic Cannabinoids. The American Journal of the Medical Sciences. 2015; 350: 59-62.

[161] Aso E, Ferrer I. Cannabinoids for treatment of Alzheimer's disease: moving toward the clinic. Frontiers in Pharmacology. 2014; 5: 37.

[162] Aso E, Palomer E, Juves S, Maldonado R, Munoz FJ, Ferrer I. CB1 agonist ACEA protects neurons and reduces the cognitive impairment of AbetaPP/PS1 mice. Journal of Alzheimer's Disease. 2012; 30: 439-459.

[163] Çakır M, Tekin S, Doğanyiğit Z, Erden Y, Soytürk M, Çiğremiş $\mathrm{Y}$, et al. Cannabinoid type 2 receptor agonist JWH-133, attenuates Okadaic acid induced spatial memory impairment and neurodegeneration in rats. Life Sciences. 2019; 217: 25-33.

[164] Aso E, Juves S, Maldonado R, Ferrer I. CB2 cannabi- noid receptor agonist ameliorates Alzheimer-like phenotype in AbetaPP/PS1 mice. Journal of Alzheimer's Disease. 2013; 35: 847-858.

[165] Wang L, Liu BJ, Cao Y, Xu WQ, Sun DS, Li MZ, et al. Deletion of Type-2 Cannabinoid Receptor Induces Alzheimer's Disease-Like Tau Pathology and Memory Impairment Through AMPK/GSK3beta Pathway. Molecular Neurobiology. 2018; 55: $4731-4744$.

[166] Tai S, Fantegrossi WE. Pharmacological and Toxicological Effects of Synthetic Cannabinoids and their Metabolites. Neuropharmacology of New Psychoactive Substances. 2017; 2011: 249-262.

[167] Esposito G, De Filippis D, Steardo L, Scuderi C, Savani C, Cuomo V, et al. CB1 receptor selective activation inhibits betaamyloid-induced iNOS protein expression in C6 cells and subsequently blunts tau protein hyperphosphorylation in co-cultured neurons. Neuroscience Letters. 2006; 404: 342-346.

[168] Rock EM, Parker LA. Constituents of Cannabis Sativa. Cannabinoids and Neuropsychiatric Disorders. 2021; 56: 1-13.

[169] Scott JC, Slomiak ST, Jones JD, Rosen AFG, Moore TM, Gur RC. Association of Cannabis with Cognitive Functioning in Adolescents and Young Adults: A Systematic Review and Meta-analysis. JAMA Psychiatry. 2018; 75: 585-595.

[170] Lubman DI, Cheetham A, Yücel M. Cannabis and adolescent brain development. Pharmacology \& Therapeutics. 2015; 148: $1-16$.

[171] Noorbakhsh S, Afzali MH, Boers E, Conrod PJ. Cognitive Function Impairments Linked to Alcohol and Cannabis Use During Adolescence: A Study of Gender Differences. Frontiers in Human Neuroscience. 2020; 14: 95.

[172] Spindle TR, Martin EL, Grabenauer M, Woodward T, Milburn MA, Vandrey R. Assessment of cognitive and psychomotor impairment, subjective effects, and blood THC concentrations following acute administration of oral and vaporized cannabis. Journal of Psychopharmacology. 2021; 35: 786-803.

[173] Figueiredo PR, Tolomeo S, Steele JD, Baldacchino A. Neurocognitive consequences of chronic cannabis use: a systematic review and meta-analysis. Neuroscience \& Biobehavioral Reviews. 2020; 108: 358-369.

[174] Ross JM, Ellingson JM, Rhee SH, Hewitt JK, Corley RP, Lessem JM, et al. Investigating the causal effect of cannabis use on cognitive function with a quasi-experimental co-twin design. Drug and Alcohol Dependence. 2020; 206: 107712.

[175] Watt G, Karl T. In vivo Evidence for Therapeutic Properties of Cannabidiol (CBD) for Alzheimer's Disease. Frontiers in Pharmacology. 2017; 8: 20.

[176] Ahmed A, Ruiz MJ, Cohen Kadosh K, Patton R, Resurreccion DM. Khat and neurobehavioral functions: A systematic review. PLoS ONE. 2021; 16: e0252900.

[177] Administration USDE. Khat. Not known. Available at: https: //www.dea.gov/factsheets/khat (Accessed: 14 November 2021).

[178] Patel NB. "Natural Amphetamine" Kha t: A Cultural Tradition or a Drug of Abuse? International Review of Neurobiology. 2015; 24: 235-255.

[179] Patel NB. Khat (Catha edulis Forsk) - and now there are three. Brain Research Bulletin. 2019; 145: 92-96.

[180] Colzato LS, Ruiz MJ, van den Wildenberg WP, Bajo MT, Hommel B. Long-term effects of chronic khat use: impaired inhibitory control. Frontiers in Psychology. 2010; 1: 219.

[181] Colzato LS, Ruiz MJ, van den Wildenberg WP, Hommel B. Khat use is associated with impaired working memory and cognitive flexibility. PLoS ONE. 2011; 6: e20602.

[182] Hoffman R, al'Absi M. Working Memory and Speed of Information Processing in Chronic Khat Users: Preliminary Findings. European Addiction Research. 2013; 19: 1-6.

[183] Colzato LS, Ruiz MJ, Wildenberg WPM, Hommel B. Khat use 
is associated with increased response conflict in humans. Human Psychopharmacology. 2012; 27: 315-321.

[184] Ismail AA, El Sanosy RM, Rohlman DS, El-Setouhy M. Neuropsychological Functioning among Chronic Khat Users in Jazan Region, Saudi Arabia. Substance Abuse. 2014; 35: 235 244.

[185] Nakajima M, Hoffman R, Al'Absi M. Poor Working Memory and Reduced Blood Pressure Levels in Concurrent Users of Khat and Tobacco. Nicotine \& Tobacco Research. 2014; 16: 279-287.

[186] Hoffman R, Al'Absi M. Concurrent use of khat and tobacco is associated with verbal learning and delayed recall deficits. Addiction. 2013; 108: 1855-1862.

[187] Bedada W, Engidawork E. The neuropsychopharmacological effects of Catha edulis in mice offspring born to mothers exposed during pregnancy and lactation. Phytotherapy Research. 2010; 24: $268-276$.

[188] Kimani ST, Nyongesa AW. Effects of single daily khat (Catha edulis) extract on spatial learning and memory in CBA mice. Behavioural Brain Research. 2008; 195: 192-197.

[189] Kimani ST, Patel NB, Kioy PG. Memory deficits associated with khat (Catha edulis) use in rodents. Metabolic Brain Disease. 2016; 31: 45-52.

[190] Administration USDE. Kratom. Not known. Available at: ht tps://www.dea.gov/factsheets/kratom (Accessed: 14 November 2021).

[191] Warner ML, Kaufman NC, Grundmann O. The pharmacology and toxicology of kratom: from traditional herb to drug of abuse. International Journal of Legal Medicine. 2016; 130: 127-138.

[192] Yusoff NHM, Suhaimi FW, Vadivelu RK, Hassan Z, Rümler A, Rotter A, et al. Abuse potential and adverse cognitive effects of mitragynine (kratom). Addiction Biology. 2016; 21: 98-110.

[193] Hassan Z, Suhaimi FW, Ramanathan S, Ling K, Effendy MA, Müller CP, et al. Mitragynine (Kratom) impairs spatial learning and hippocampal synaptic transmission in rats. Journal of Psychopharmacology. 2019; 33: 908-918.

[194] Iman IN, Ahmad NAZ, Mohd Yusof NA, Talib UN, Norazit A, Kumar J, et al. Mitragynine (Kratom)-Induced Cognitive Impairments in Mice Resemble Delta9-THC and Morphine Effects: Reversal by Cannabinoid CB1 Receptor Antagonism. Frontiers in Pharmacology. 2021; 12: 708055.

[195] Ismail NIW, Jayabalan N, Mansor SM, Müller CP, Muzaimi M. Chronic mitragynine (kratom) enhances punishment resistance in natural reward seeking and impairs place learning in mice. Addiction Biology. 2017; 22: 967-976.

[196] Prosser JM, Nelson LS. The Toxicology of Bath Salts: a Review of Synthetic Cathinones. Journal of Medical Toxicology. 2012; 8: 33-42.

[197] Katz DP, Bhattacharya D, Bhattacharya S, Deruiter J, Clark CR, Suppiramaniam V, et al. Synthetic cathinones: "a khat and mouse game". Toxicology Letters. 2014; 229: 349-356.

[198] Freeman TP, Morgan CJA, Vaughn-Jones J, Hussain N, Karimi $\mathrm{K}$, Curran HV. Cognitive and subjective effects of mephedrone and factors influencing use of a 'new legal high'. Addiction. 2012; 107: 792-800.

[199] Herzig DA, Brooks R, Mohr C. Inferring about individual drug and schizotypy effects on cognitive functioning in polydrug using mephedrone users before and after clubbing. Human Psychopharmacology. 2013; 28: 168-182.

[200] de Sousa Fernandes Perna E, Papaseit E, Pérez-Mañá C, Mateus J, Theunissen E, Kuypers K, et al. Neurocognitive performance following acute mephedrone administration, with and without alcohol. Journal of Psychopharmacology. 2016; 30: 1305-1312.

[201] Grochecki P, Smaga I, Lopatynska-Mazurek M, GibulaTarlowska E, Kedzierska E, Listos J, et al. Effects of
Mephedrone and Amphetamine Exposure during Adolescence on Spatial Memory in Adulthood: Behavioral and Neurochemical Analysis. International Journal of Molecular Sciences. 2021; 22: 589 .

[202] Naseri G, Fazel A, Golalipour MJ, Haghir H, Sadeghian H, Mojarrad M, et al. Exposure to mephedrone during gestation increases the risk of stillbirth and induces hippocampal neurotoxicity in mice offspring. Neurotoxicology and Teratology. 2018; 67: $10-17$.

[203] Sewalia K, Watterson LR, Hryciw A, Belloc A, Ortiz JB, Olive MF. Neurocognitive dysfunction following repeated binge-like self-administration of the synthetic cathinone 3, 4-methylenedioxypyrovalerone (MDPV). Neuropharmacology. 2018; 134: 36-45.

[204] Colon-Perez LM, Tran K, Thompson K, Pace MC, Blum K, Goldberger BA, et al. The Psychoactive Designer Drug and Bath Salt Constituent MDPV Causes Widespread Disruption of Brain Functional Connectivity. Neuropsychopharmacology. 2016; 41: 2352-2365.

[205] den Hollander B, Rozov S, Linden A, Uusi-Oukari M, Ojanperä I, Korpi ER. Long-term cognitive and neurochemical effects of "bath salt" designer drugs methylone and mephedrone. Pharmacology Biochemistry and Behavior. 2013; 103: 501-509.

[206] Ciudad-Roberts A, Duart-Castells L, Camarasa J, Pubill D, Escubedo E. The combination of ethanol with mephedrone increases the signs of neurotoxicity and impairs neurogenesis and learning in adolescent CD-1 mice. Toxicology and Applied Pharmacology. 2016; 293: 10-20.

[207] Motbey CP, Karanges E, Li KM, Wilkinson S, Winstock AR, Ramsay J, et al. Mephedrone in adolescent rats: residual memory impairment and acute but not lasting 5-HT depletion. PLoS ONE. 2012; 7: e45473.

[208] Weed PF, Leonard ST, Sankaranarayanan A, Winsauer PJ. Estradiol administration to ovariectomized rats potentiates mephedrone-induced disruptions of nonspatial learning. Journal of the Experimental Analysis of Behavior. 2014; 101: 303-315.

[209] Leyrer-Jackson JM, Nagy EK, Olive MF. Cognitive deficits and neurotoxicity induced by synthetic cathinones: is there a role for neuroinflammation? Psychopharmacology. 2019; 236: 1079-1095.

[210] GBD 2017 Disease and Injury Incidence and Prevalence Collaborators. Global, regional, and national incidence, prevalence, and years lived with disability for 354 diseases and injuries for 195 countries and territories, 1990-2017: a systematic analysis for the Global Burden of Disease Study 2017. The Lancet. 2018; 392: 1789-1858.

[211] Akbari V, Ghobadi S, Mohammadi S, Khodarahmi R. The antidepressant drug; trazodone inhibits Tau amyloidogenesis: Prospects for prophylaxis and treatment of AD. Archives of Biochemistry and Biophysics. 2020; 679: 108218.

[212] Arnsten AFT, Datta D, Del Tredici K, Braak H. Hypothesis: Tau pathology is an initiating factor in sporadic Alzheimer's disease. Alzheimer's \& Dementia. 2021; 17: 115-124.

[213] Yao K, Zhao YF, Zu HB. Melatonin receptor stimulation by agomelatine prevents $\mathrm{A} \beta$-induced tau phosphorylation and oxidative damage in PC12 cells. Drug Design Development and Therapy. 2019; 13: 387-396.

[214] Li H, Wang X, Yu H, Zhu J, Jin H, Wang A, et al. Combining in vitro and in silico Approaches to Find New Candidate Drugs Targeting the Pathological Proteins Related to the Alzheimer's Disease. Current Neuropharmacology. 2018; 16: 758-768.

[215] Zorkina Y, Abramova O, Ushakova V, Morozova A, Zubkov E, Valikhov M, et al. Nano Carrier Drug Delivery Systems for the Treatment of Neuropsychiatric Disorders: Advantages and Limitations. Molecules. 2020; 25: 5294. 